\title{
QFD no desenvolvimento de novos produtos: um estudo sobre a sua introdução em uma empresa adotando a pesquisa-ação como abordagem metodológica
}

Paulo A. Cauchick Miguel EPUSP

\begin{abstract}
RESUMO
Organizações de vários setores industriais vêm estruturando seu processo de desenvolvimento de novos produtos (PDP) e introduzindo métodos e técnicas para dar suporte a esse processo. Nesse contexto, este trabalho objetiva apresentar a restruturação de um PDP e a implementação de um método de suporte ao desenvolvimento de novos produtos, o desdobramento da função qualidade (QFD). O trabalho foi conduzido em uma empresa fornecedora para o setor de embalagens por meio dos ciclos da pesquisa-ação, cujos resultados são descritos tendo como contexto a estruturação do PDP e a adoção do QFD. O PDP reestruturado, resultante da base teórica adotada, proporcionou uma melhoria para o desenvolvimento de novos produtos comparativamente à versão anterior, alocando com maior precisão as atividades de desenvolvimento de novos produtos. Em relação ao uso do QFD, o método proporcionou um suporte adequado a estas atividades, no sentido de organização, registro das informações e de uma sequência lógica para as atividades associadas às dimensões de mercado e de desenvolvimento das especificações. Finalmente, conclui-se assim que o trabalho cumpriu os objetivos propostos possibilitado pela abordagem de pesquisa-ação.
\end{abstract}

\section{QFD in new product development: a study on its introduction in a company adopting action-research as the methodological approach}

\begin{abstract}
Organizations from various industrial sectors have structured their new product development process (NPD) and introduced methods and techniques to support this process. In this context, this paper aims at presenting the restructure of NPD and the implementation of a method to support it, Quality Function Deployment (QFD). The work was conducted in a company that supplies to the packaging sector through the cycles of action-research. The results are described based on the restructure of NDP and QFD adoption. The restructured NPD, as a result from the theoretical basis, enables to enhance product development in comparison to the previous version, by distributing its activities more precisely. Concerning QFD, the method enables an adequate support to the new product development activities in the sense of data recording and logical sequence of activities related to the dimensions of market and specifications. Finally, the paper concludes that this work fulfil its objectives enabled by action research approach.
\end{abstract}

\section{KEY WORDS}

product development, QFD, quality function deployment, case study. 


\section{INTRODUÇÃO}

É notória hoje a necessidade das empresas não somente em introduzir produtos que venham a atender às expectativas do segmento de mercado a que se destinam mas também que venham fazer frente à concorrência. No entanto, somente o lançamento de novos produtos não é suficiente. Pesquisas mostram que uma grande parte dos produtos lançados no mercado dos países desenvolvidos fracassou; para cada 100 ideias de produtos, somente 4 obtiveram o sucesso esperado, ou seja, uma taxa de 1 sucesso para cada 25 ideias (GRIFFIN, 1997).

de novos produtos de uma empresa, por meio de uma intervenção pela abordagem da pesquisa-ação. No escopo deste objetivo geral, dois objetivos intermediários são considerados: a reestruturação do processo de desenvolvimento de novos produtos e a implementação do QFD neste processo. A aplicação do QFD é considerada como um construct importante no gerenciamento de operações no desenvolvimento de novos produtos como identificado por Tan e Wisner (2003), dentro do contexto de uma estruturação do PDP.

Deve-se enfatizar que o presente trabalho apresenta características que o poderiam classificar dentro da abordagem metodológica de estudo de caso. No entanto, houve uma intervenção efetiva na empresa (diferentemente da abordagem não participante que é predominante no estudo de caso). Assim, caracteriza-se a abordagem adotada como pesquisa-ação, descrita no tópico seguinte, voltada para o tratamento de um problema empírico real por meio da intervenção de um pesquisador em estreita cooperação com os envolvidos na pesquisa, conforme estabeleci-

Um dos fatores de sucesso na introdução de novos produtos está relacionado à eficácia na oferta de produtos no mercado. Embora essa possa ser considerada uma condição necessária, não é suficiente, pois, além disso, é preciso que haja um meio organizacional adequado, que propicie atingir tal eficácia de forma eficiente, ou seja, de modo mais rápido, com um menor consumo de recursos e com custos reduzidos. Isso significa então "desenvolver os produtos corretos" e "desenvolvê-los corretamente", parafraseando Cooper et al. (2000). Assim, as empresas devem considerar um processo organizacional adequado para desenvolver seus produtos. Esse processo é, geralmente, obtido por meio de uma estrutura organizacional, que Cooper (1993) define como um mapa, um modelo ou um processo conceitual para guiar o projeto de um novo produto, transformando oportunidades de mercado aliadas às possibilidades técnicas em dados para a produção e lançamento do produto (CLARK; FUJIMOTO, 1991).

Concomitantemente à organização do PDP (processo de desenvolvimento de novos produtos), uma extensa quantidade de atividades e tarefas devem ser conduzidas, que envolvem desde a concepção inicial do produto até seu lançamento no mercado. Para dar suporte a essas atividades, diversos métodos e técnicas têm sido empregados. Parte da literatura em desenvolvimento de novos produtos é prescritiva no sentido de indicar métodos específicos (e.g. AKAO, 1990) ou um conjunto desses métodos (e.g. FRANCESCHINI; ROSSETTO, 1999).

Nesse contexto, o objetivo geral do presente trabalho é demonstrar a reestruturação do sistema de desenvolvimento do por Coughlan e Coghlan (2002). Nessa investigação, pretende-se, portanto, em linhas gerais, acertar o descompasso entre os aspectos empíricos da pesquisa em relação à teoria vigente sobre o tema em estudo. Assim, a condução dos dois objetivos intermediários visa a consecução do objetivo geral do presente trabalho.

\section{REFERENCIAL METODOLÓGICO}

A abordagem metodológica do presente trabalho é caracterizada como pesquisa-ação, considerando os trabalhos de Eden e Huxham (1996), Thiollent (1997), Checkland e Holwell (1998), Coughlan e Coghlan (2002), incluindo trabalhos mais aplicados desta abordagem, tais como os relatos de Cheng e Sarantopoulos (1995), Karlsson e Åhldtröm (1996) e Bennett e Lee (2000).

\subsection{Estratégia metodológica - pesquisa-ação}

A pesquisa-ação é um trabalho de natureza empírica, concebido e realizado em estreita associação com a resolução de um problema coletivo, no qual os pesquisadores e participantes representativos da situação estão envolvidos de modo cooperativo ou participativo (THIOLLENT, 1997), objetivando endereçar este problema de pesquisa em uma organização (EDEN; HUXHAM, 1996). Cabe ainda considerar que, geralmente, os pesquisadores que trabalham nessa abordagem não lidam com hipóteses, mas com temas de pesquisa e desafios de cunho organizacional (CHECKLAND; 
HOLWELL, 1998). Expandindo essas colocações, Coughlan e Coghlan (2002) acrescentam que a pesquisa-ação apresenta as características principais listadas na primeira coluna do Quadro 1. Na segunda coluna é apresentada a relação de cada uma dessas características, buscando uma melhor caracterização metodológica sobre a abordagem adotada no presente trabalho.

No Quadro 1 consideram-se as características desejáveis para a condução de pesquisa-ação, observando que estas devem ser levadas em conta desde o momento da sua concepção, ou seja, a pesquisa deve ser planejada como tal. De modo geral, esta abordagem de pesquisa compreende três fases principais: uma preliminar, um ciclo de condução e uma meta fase, ilustradas na Figura 1 e descritas na sequência. O ciclo de condução da pesquisa compreende seis passos, enquanto que a meta fase está presente em cada um desses seis passos.

Primeira Fase - Estudo Preliminar: no presente trabalho, esta fase é caracterizada a partir de reuniões de planejamento, realizadas durante oito meses anteriores ao início da im-

Quadro 1: Características da pesquisa-ação e enquadramento no trabalho.

Características

O pesquisador toma ação

(não é mero observador)

A pesquisa-ação envolve dois objetivos: 1 . solucionar um problema; 2. contribuir para a ciência

A pesquisa-ação é interativa (cooperação e interatividade entre os envolvidos)

A pesquisa-ação objetiva desenvolver um entendimento holístico

A pesquisa-ação é fundamentalmente relacionada à mudança

A pesquisa-ação pode incluir diferentes métodos e técnicas de coleta de dados (quantitativas e qualitativas)

A pesquisa-ação deve ser conduzida em tempo real (um estudo de caso "vivo")

A pesquisa-ação requer critérios próprios de qualidade para sua avaliação
Presente Trabalho

Atuação do pesquisador por meio da participação ativa em reuniões de projetos de desenvolvimento de novos produtos e observação não participativa de parte dos trabalhos de gestão de portfólio e de restruturação do processo de desenvolvimento de produtos. Esse acompanhamento proporcionou uma melhor interação entre as três iniciativas de implementação na empresa em estudo.

A busca de solução foi para solucionar uma limitação associada ao desenvolvimento de novos produtos. A contribuição teórica esperada é direcionada para a implementação de um método de apoio ao desenvolvimento de produtos (QFD), de forma combinada com a restruturação de um processo para desenvolvimento de novos produtos, destacando-se, principalmente, a relação das atividades de trabalho com o método em relação ao momento em que essas atividades devem ser conduzidas nos estágios de desenvolvimento de produto

O nível de interatividade (com os envolvidos e com a organização), bem como a extensão (de tempo) pela qual essa interatividade ocorreu por meio da participação ativa em várias reuniões de projetos de desenvolvimento de novos produtos, sendo possível uma interatividade intensa com os envolvidos, de diferentes níveis hierárquicos e provenientes de diversas áreas funcionais da organização. Como referência, houve a participação em 93 reuniões de projeto em 42 dias em um ano

0 trabalho proporcionou um entendimento abrangente do problema a ser tratado e também da organização pelas seguintes razões: considera uma visão abrangente, sob o ponto de vista teórico, pois proporcionou um amplo estudo da literatura; considera uma visão abrangente sob o ponto de vista empírico e ao mesmo tempo integradora, pois aborda a inter-relação entre três frentes de trabalho sendo implantadas; necessidade de compreensão do contexto onde a pesquisa foi conduzida e, consequentemente, uma ligação entre o campo teórico e o empírico

A mudança é inerente a esse projeto, pois seu escopo é de uma implementação em um ambiente de restruturação do processo de desenvolvimento de novos produtos em uma empresa. Essa mudança envolve um trabalho de longo prazo (mais de três anos), aferindo as alterações ocorridas a partir da intervenção do pesquisador em variados níveis de intensidade

Foram adotadas tanto técnicas qualitativas quanto quantitativas para a coleta e análise dos dados, por meio de registro de reuniões de projeto, redação de relatórios sobre o andamento do trabalho, bem como elaboração de apresentações internas para os envolvidos diretamente com o trabalho e para as gerências e direção da empresa. Foram também empregados levantamentos de cunho quantitativo ("mini"- surveys como para verificação do nível de conhecimento dos membros das equipes de projeto), bem como de cunho qualitativo (interpretações dadas para as informações qualitativas das reuniões de projeto)

Pelo fato de o trabalho ter sido conduzido pelo período de 43 meses, de forma ininterrupta, com participação na empresa de um dia por semana, conduzindo os aspectos de intervenção e influência nas decisões organizacionais em tempo real

Além da literatura de referência para a condução do trabalho, foram desenvolvidos critérios específicos para a avaliação da pesquisa, que incluíam auditorias por pesquisador não diretamente envolvido com o projeto, apresentações para a direção geral da empresa e Comitê de Projetos e outras apresentações feitas na própria empresa, para seus clientes, fornecedores, além de eventos abertos ao público 
plantação, onde foi melhor estudado o contexto da pesquisa para a condução do trabalho, definindo-se os seus propósitos com base em trabalhos anteriores similares (e.g. CHENG; SARANTOPOULOS, 1995). A ação para a presente pesquisa foi direcionada no sentido de superar as seguintes dificuldades da empresa em desenvolver novos produtos:

- Não era claro como uma ideia advinda do mercado ou de outras fontes deveria ser desenvolvida no projeto de um novo produto. Existia uma dispersão dessas idéias, bem como não havia uma sequência clara para desenvolvê-las;

- O processo de desenvolvimento de novos produtos era excessivamente centrado na área de $\mathrm{P} \& \mathrm{D}$, dificultando o envolvimento e comprometimento de outras áreas funcionais;

- Faltava um canal definido para os dados de entrada para desenvolver o novo produto. Geralmente, esses dados (por exemplo, a qualidade exigida pelos clientes) ficavam dispersos na organização, além de não permitir o aproveitamento das lições aprendidas com outros projetos já desenvolvidos.

Assim, os seguintes propósitos principais foram estabelecidos: a implementação do QFD no PDP e a restruturação desse processo de desenvolvimento, além do gerenciamento da carteira de projetos (gestão de portfólio). Os dois primeiros propósitos são abordados no presente trabalho, fazendo parte do seu escopo, enquanto que o terceiro encontra-se fora da delimitação da presente investigação. No caso específico deste artigo, as questões da pesquisa são relacionadas a melhor maneira de conduzir a implementação do QFD, método escolhido para dar suporte ao processo de desenvolvimento de produtos a partir da restruturação organizacional deste processo.

Segunda Fase - Ciclo de Condução pelos Seis Passos: o Quadro 2 apresenta uma síntese dos seis passos com base na literatura sobre metodologia de pesquisa. É importante observar que a tabela foi construída com base na literatura porém inclui as práticas adotadas pelo autor.

Para a condução da pesquisa, pode haver um ciclo mais amplo (no presente trabalho aproximadamente 3,5 anos), para o projeto de pesquisa como um todo e outros ciclos menores. No presente trabalho, pode-se identificar três ciclos mostrados no Quadro 3.

Terceira (Meta) Fase - Monitoramento: esta fase compreende uma verificação de cada um dos seis passos anteriores, no sentido de identificar qual é o aprendizado gerado na condução da pesquisa-ação. Esse monitoramento pode estar presente de diferentes maneiras, conforme cada passo do ciclo de condução. Do lado organizacional, pode haver o estabelecimento de um grupo diretivo durante a condução da

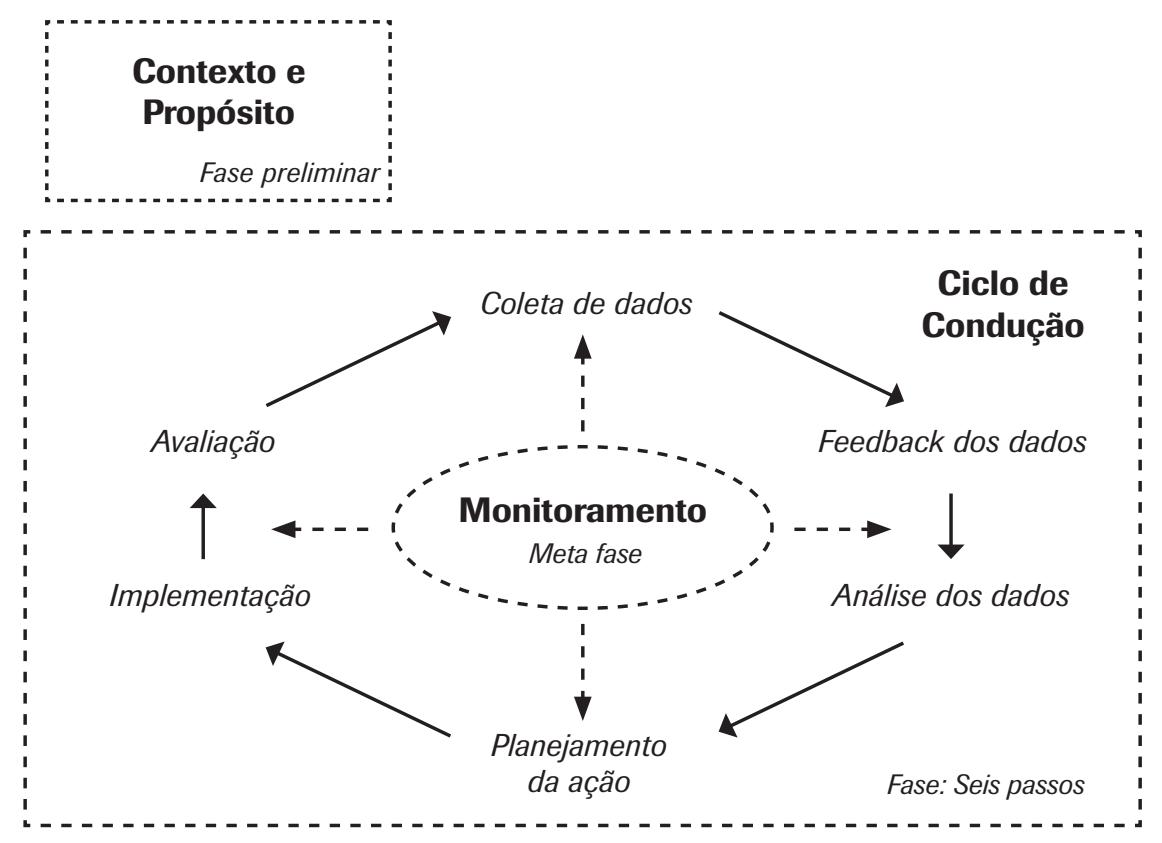

Figura 1: Ciclo da pesquisa-ação.

Fonte: adaptado de Coughalan e Coghlan, 2002. 
pesquisa-ação, nesse caso com maior interesse nos resultados práticos do trabalho (COUGHALAN; COGHLAN, 2002). Do lado da própria pesquisa, caracteriza-se como a contribuição gerada para a teoria vigente, que pode emergir dos dados ou do próprio uso da teoria na prática (EDEN; HUXHAM, 1996). Este monitoramento ocorreu de diversas maneiras, sendo a principal relacionando-se às decisões e resultados empíricos do trabalho com o que já é estabelecido pela teoria vigente. Por exemplo, sobre aplicação do QFD, pode-se citar a análise dos trabalhos de Akao (1990) no Japão e o de Cheng et al. (1995) no Brasil. Em paralelo, outras aplicações do método foram analisadas (e.g. YEUNG; LAU, 1997), não somente objetivando dar maior suporte para a condução do trabalho, mas também para identificar os níveis de apren- dizado gerados pela condução dessa pesquisa-ação. Para monitorar o trabalho, toda a sua condução foi registrada, na forma eletrônica e em papel, visando análise posterior.

\subsection{Unidade de análise e delineamento da pesquisa}

O objeto de análise é a empresa onde o estudo foi realizado, porém a unidade de análise é o processo de PDP da empresa. Na ocasião do estudo, a empresa pertencia a um dos maiores grupos privados brasileiros da América Latina, que agregava 60 outras organizações de diversos setores industriais, produzindo e comercializando filmes poliméricos para embalagens. A organização possuía cerca de 350 funcionários, gerando um resultado anual de mais de R\$ 100 milhões, e vinha implementando algumas práticas

Quadro 2: Seis passos do ciclo de condução a partir de Coughlan e Coghlan, 2002.

\begin{tabular}{|c|c|c|}
\hline Passo & Descrição & Meios da Pesquisa \\
\hline $\begin{array}{l}\text { Coleta de Dados } \\
\text { e registro dos } \\
\text { dados }\end{array}$ & $\begin{array}{l}\text { Dados são gerados por meio do } \\
\text { envolvimento com o processo } \\
\text { organizacional }\end{array}$ & $\begin{array}{l}\text { Participação nos projetos de desenvolvimento de novos produtos; reuniões } \\
\text { para discussão do processo de desenvolvimento de produtos; análise } \\
\text { documental (GIL, 2002); diário da pesquisa para registro (McNIFF et al., 1996) }\end{array}$ \\
\hline $\begin{array}{l}\text { Feedback dos } \\
\text { Dados }\end{array}$ & $\begin{array}{l}\text { Os dados são retornados } \\
\text { para a organização visando } \\
\text { disponibilizá-los para análise }\end{array}$ & $\begin{array}{l}\text { Relatórios elaborados pelo pesquisador; apresentações feitas para as equipes } \\
\text { de projeto, para o Comitê de Projetos e para a alta direção; feedback informais } \\
\text { em horários de almoço, café e atividades sociais esporádicas de feedback }\end{array}$ \\
\hline $\begin{array}{l}\text { Análise dos } \\
\text { Dados }\end{array}$ & $\begin{array}{l}\text { Análise conjunta realizada } \\
\text { pelo pesquisador e membros } \\
\text { envolvidos (por exemplo } \\
\text { membros dos times de trabalho) }\end{array}$ & $\begin{array}{l}\text { Apresentações feitas pelas equipes de projeto para o Comitê de Projetos e para } \\
\text { a alta direção; organização dos dados em planilhas e relatórios. Os critérios } \\
\text { de análise necessitam estar relacionados aos propósitos da pesquisa e da } \\
\text { intervenção }\end{array}$ \\
\hline $\begin{array}{l}\text { Planejamento } \\
\text { da ação }\end{array}$ & $\begin{array}{l}\text { Atividade conjunta que } \\
\text { estabelece o que vai ser feito e } \\
\text { com que prazo }\end{array}$ & $\begin{array}{l}\text { Planejamento de atividades de curto prazo (semanais) no final de cada reunião } \\
\text { de projeto e no final de cada ciclo de condução (ver Quadro 3) }\end{array}$ \\
\hline $\begin{array}{l}\text { Implementação } \\
\text { da ação }\end{array}$ & $\begin{array}{l}\text { A ação estabelecida é então } \\
\text { implementada visando promover } \\
\text { as mudanças planejadas }\end{array}$ & $\begin{array}{l}\text { Aplicação do QFD na condução dos projetos de novos produtos, redação de } \\
\text { procedimentos operacionais para o QFD (por exemplo, criação de um manual) } \\
\text { e para o processo de desenvolvimento em colaboração com os envolvidos }\end{array}$ \\
\hline Avaliação & $\begin{array}{l}\text { Reflexão dos resultados } \\
\text { esperados ou não decorrentes } \\
\text { da implementação da ação }\end{array}$ & $\begin{array}{l}\text { Apresentações de avaliação feitas para o Comitê de Projetos e para a alta } \\
\text { direção e para pesquisador externo às atividades; relatórios periódicos de } \\
\text { andamento dos projetos }\end{array}$ \\
\hline
\end{tabular}

Quadro 3: Ciclos principais desta pesquisa-ação.

\begin{tabular}{llll}
\multicolumn{1}{c}{ Propósitos } & \multicolumn{1}{c}{ Ciclo 1 } & Ciclo 2 \\
\hline $\begin{array}{l}\text { Restruturação do processo } \\
\text { de desenvolvimento de novos } \\
\text { produtos }\end{array}$ & $\begin{array}{l}\text { Realizar um diagnóstico e } \\
\text { propor um processo }\end{array}$ & $\begin{array}{l}\text { Implementar o novo processo } \\
\text { de desenvolvimento }\end{array}$ & $\begin{array}{l}\text { Ajustar o processo de } \\
\text { desenvolvimento (revisar as atividades }\end{array}$ \\
$\begin{array}{l}\text { Implementação de um método } \\
\text { para suporte que pudesse lidar } \\
\text { com as demandas dos clientes }\end{array}$ & Conduzir um projeto piloto & Multiplicar a aplicação no & Integrar o QFD ao processo de \\
com aplicação do QFD & piloto para outros projetos & desenvolvimento (nos estágios e & gates)
\end{tabular}


organizacionais (certificação ISO 9001: 2000 e implantação do TPM - Total Productive Maintenance). Notadamente, a curva de produção nos últimos anos vinha se acentuando positivamente (produção de mais de 64.000 t/ano), numa produção por encomenda.

\section{$\Delta$ pesquisa-ação é de natureza empírica, concebida e realizada para a resolução de um problema coletivo, onde os pesquisadores e participantes estão envolvidos de modo cooperativo.}

A análise dos dados seguiu uma lógica indutiva, ou seja, estabelece-se uma cadeia de raciocínio partindo-se de dados particulares e tenta-se chegar a fatos gerais, como estabelecido por Andrade (2002).

A partir do que foi anteriormente descrito, o Quadro 6 apresenta uma síntese metodológica do trabalho, indicando os pontos considerados como mais relevantes, em termos da estratégia de pesquisa adotada e métodos e técnicas de pesquisa utilizados. É importante ressaltar que os métodos e técnicas apresentados são comuns a outros tipos de abordagens metodológicas, como no estudo de caso, e são

O Quadro 4 mostra o delineamento da pesquisa. Os dados de caráter qualitativo foram interpretados a partir dos meios de registro citados, principalmente com base nas anotações no diário de pesquisa e na organização destes, como no caso de alguns dos projetos ilustrados no Quadro 5. A coluna "origem" significa de onde veio a demanda de desenvolvimento do produto enquanto que as colunas "status" e "tecnologia" referem-se, respectivamente, a fase do projeto em um dado momento observado e a sua maturidade tecnológica em termos de grau de novidade para o produto e/ou para o processo de manufatura. A coluna "lead time" compreende a duração do projeto, a coluna "time" relata a quantidade de participantes na equipe de desenvolvimento e a coluna " $\mathrm{n}$ o de funções" refere-se à origem dos participantes, em termos de áreas funcionais (alguma equipes tinham mais de um participante de uma determinada área funcional, por exemplo engenharia do produto). essenciais para a condução da pesquisa-ação, muitas vezes negligenciados.

\section{REFERENCIAL TEÓRICO}

A proposição para a gestão de desenvolvimento de produtos usada nesse trabalho é aquela proposta por Cheng (2000). Seu conteúdo é centrado na seguintes vertentes teóricas: gestão de portfólio, organização para o desenvolvimento de produto (processo de desenvolvimento) e o desdobramento da função qualidade (QFD), sendo os dois últimos mais diretamente relacionadas ao presente trabalho.

O desenvolvimento de produtos é um campo vasto de conhecimento que pode ser visto sob diferentes ângulos (CHENG, 2000), constituindo-se de uma série de atividades que podem ser estruturadas nos níveis estratégico e organizacional. A Figura 2 ilustra um sistema de desenvolvimento

Quadro 4: Delineamento da pesquisa.

\begin{tabular}{ll}
\hline \multicolumn{1}{c}{ Aspecto Analisado } & \multicolumn{1}{c}{ Conceitos e Práticas } \\
\hline $\begin{array}{l}\text { Seleção do objeto de } \\
\text { análise }\end{array}$ & $\begin{array}{l}\text { Empresa do setor de plásticos, produtora de filmes flexíveis de BOPP (polipropileno biorientado) para } \\
\text { embalagens }\end{array}$ \\
$\begin{array}{l}\text { Elaboração de referencial } \\
\text { teórico sobre DP }\end{array}$ & $\begin{array}{l}\text { Estudo sobre os modelos referenciais para desenvolvimento de produto; por exemplo, os trabalhos de Clark } \\
\text { e Wheelwright (1993), Cooper (1993), Rahman (1995), Griffin e Page (1996), Gunasekaran (1998), Peters } \\
\text { (1999), Phillips et al. (1999) }\end{array}$ \\
$\begin{array}{l}\text { Elaboração de referencial } \\
\text { teórico sobre o QFD }\end{array}$ & $\begin{array}{l}\text { Estudo sobre os benefícios e dificuldades de implantação do QFD, baseado nos trabalhos de Miguel e } \\
\text { (2004) }\end{array}$ \\
Coleta dos dados & $\begin{array}{l}\text { Uso de diário de pesquisa; participação nas reuniões de projeto de desenvolvimento de novos produtos; } \\
\text { análise documental (registros de projetos, relatórios, atas, etc.); entrevistas; surveys com os envolvidos (em } \\
\text { pequena escala) }\end{array}$ \\
& $\begin{array}{l}\text { Interpretação de dados qualitativos; lógica indutiva; reflexões com base nas anotações do diário de } \\
\text { pesquisa; dados de desenvolvimento de mais de 10 projetos analisados (Quadro 5) }\end{array}$ \\
\hline Análise dos dados &
\end{tabular}


de novos produtos. O nível estratégico compreende o alinhamento das metas e objetivos da empresa, considerando as particularidades do seu negócio, com o conjunto de projetos em desenvolvimento, relacionando esse conjunto com a capacidade de desenvolvimento de produtos da organização, cujo termo geralmente empregado na literatura é "gestão de portfólio" (MEYER, 1997; COOPER et al., 1997a; 1997b; 2000).

A gestão do portfólio é um processo de decisão dinâmico, pelo qual um conjunto de novos projetos de produtos são constantemente atualizados e revisados (COOPER et al., 1998). Nesse processo, novos projetos são avaliados, selecionados, e priorizados. São verificados aqueles projetos que estrategicamente são vitais para serem executados, seja pelo aspecto tecnológico ou mercadológico (lado esquerdo na Figura 2). O processo de decisão de portfólio engloba uma série de outros processos de tomada de decisão, como no caso das revisões periódicas da carteira de projetos, visualizando-os e comparando-os entre si (COOPER et al., 1998). Também tomam-se decisões do tipo siga/interrompa para projetos individuais, além de se desenvolver uma nova estratégia de produtos para o negócio, completado pela decisão de alocação estratégica de recursos. É importante destacar que existem diferenças no projeto de um novo produto no que tange a extensão de alterações tanto para o produto quanto para o processo. Nesse sentido, Clark e Wheelwright (1993) classificam os projetos como plataforma, derivativos, de ruptura ou de parceria, como ilustrado na Figura 3.

Em suma, a prática de gestão de portfólio envolve a decisão sobre quais projetos devem ser acrescentados à carteira ativa de projetos de uma empresa, definição do projeto e seus objetivos, prazos e recursos necessários. Uma vez feita este planejamento, a atenção é voltada para o desenvolvimento de cada projeto individualmente (lado direito da Figura 2). A fim que isso ocorra, geralmente as empresas utilizam processos estruturados de desenvolvimento, destacados a seguir.

O nível organizacional é voltado para a condução dos projetos específicos, ou seja, é responsável pelo desenvolvimento propriamente dito, gerenciando e executando o projeto do novo produto. Esse nível concentra esforços no processo em si e também na utilização de métodos e técnicas que suportem esse processo. Grande parte da literatura

Quadro 5: Características relevantes dos projetos.

\begin{tabular}{|c|c|c|c|c|c|c|}
\hline \multirow{2}{*}{$\begin{array}{l}\text { Projetos } \\
\text { (c/ QFD) }\end{array}$} & \multicolumn{6}{|c|}{ Características } \\
\hline & Origem & Status & Tecnologia & Lead time & Time & № funções \\
\hline P-00 & Melhorar produto existente & Em produção & Antiga & 9 meses & 9 & 6 \\
\hline P-01 & Gap em performance & Em produção & Moderada/te nova & 15 meses & 5 & 4 \\
\hline P-06 & Melhorar produto existente & Em produção & Antiga & 16 meses & 6 & 5 \\
\hline P-07 & Exigência do cliente & Em produção & Moderada/te nova & 16 meses & 7 & 5 \\
\hline P-12 & Oportunidade de mercado & Desenvolvi/to do conceito & Nova & Abortado & 4 & 3 \\
\hline P-14 & Oportunidade de mercado & Ramp up & Nova & Não concluído & 4 & 4 \\
\hline P-15 & Exigência do cliente & Desenvolvi/to & Nova & Não concluído & 3 & 3 \\
\hline
\end{tabular}

Quadro 6: Síntese metodológica.

\begin{tabular}{ll}
\hline \multicolumn{1}{c}{ Aspecto Metodológico } & \multicolumn{1}{c}{ Categorização } \\
\hline Abordagem & Pesquisa-ação \\
Objeto de análise & Empresa \\
Unidade de análise & Processo de desenvolvimento de novos produtos \\
Tipos dos dados & Predominantemente qualitativos \\
Coleta dos dados & Múltiplas fontes de evidência; triangulação \\
Análise dos dados & Lógica indutiva \\
Qualidade e validade da pesquisa & Imparcialidade e isenção; apresentações públicas; uso de múltiplas fontes de evidência \\
\hline
\end{tabular}


dedicada a gestão de desenvolvimento de produtos é voltada para aspectos relacionados aos processos de desenvolvimento, ou seja, concentra-se no nível operacional. Geralmente, este processo de desenvolvimento considera a seguinte sequência: geração de ideia, investigação, desenvolvimento do projeto, produção, e lançamento. Nesse sentido, existem diversos modelos de desenvolvimento que buscam a condução desse processo, destacando-se dentre eles a estrutura do funil de Clark e Wheelwright (1993) e a estrutura genérica do stage-gate, proposta por Cooper (1993).

$\mathrm{O}$ funil de desenvolvimento consiste em quatro estágios compreendidos por (CLARK; WHEELWRIGHT, 1993): conceito e desenvolvimento, planejamento do produto, engenharia do processo e produto, e produção piloto e aumento de produção (ramp-up). Dentre as empresas que implantaram o funil de desenvolvimento estão a Natura (NASCIMENTO; MARX, 2001) e a Sandvik (SANTOS; PASCHOARELLI, 1998).

A estrutura denominada genericamente de "stage-gate" é uma abordagem que divide o processo de desenvolvimento em estágios discretos e identificáveis, onde cada um é com- pletado para que o projeto possa progredir para o estágio seguinte, antes passando por um ponto de decisão denominado de gate; compreende os seguintes estágios (COOPER, 1993): investigação preliminar; investigação detalhada; desenvolvimento; validação e teste, e produção e lançamento (Figura 4). Dentre as empresas que adotaram o stage-gate e suas variantes estão (PHILLIPS et al., 1999): Bombardier Aerospace Group, Kodak, General Electric, Lucas Industries, Rolls-Royce e Motorola.

As melhores práticas para desenvolvimento de produto podem ser apoiadas pela implementação da abordagem do stage-gate (GRIFFIN, 1997). A realização de cada um dos estágios de desenvolvimento, tomando o stage-gate como referência, envolve a aplicação de métodos e técnicas apropriados, que dependem do setor industrial e do negócio da organização. Diversos métodos e técnicas têm sido utilizados, tais como mapas de preferência, sistemas CAD/CAM/ CAE (computer aided design/computer aided manufacturing/ computer aided engineering, respectivamente projeto auxiliado por computador, manufatura auxiliada por computador e engenharia auxiliada por computador), DFM/DFA (design
PORTFÓLIO

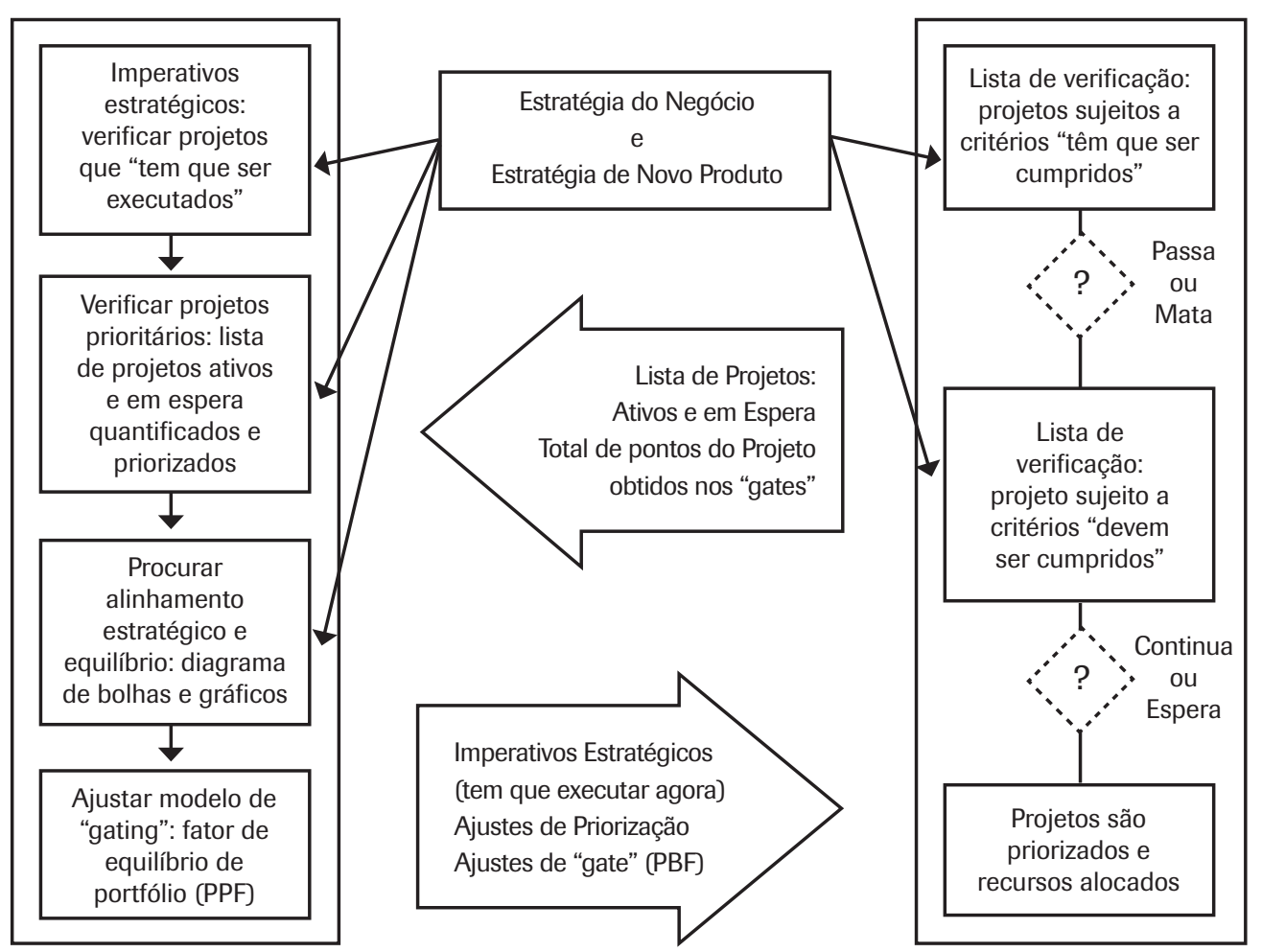

Figura 2: Gestão de portfólio e do desenvolvimento de produtos (COOPER et al., 1998). 
for manufacturing/design for assembly, respectivamente projeto para a manufatura e projeto para a montagem), QFD (quality function deployment, ou desdobramento da função qualidade), DOE (design of experiments, ou planejamento de experimentos), FTA (fault tree analysis, ou árvore de análise de falhas), FMEA (failure mode and effects analysis, ou análise dos modos e efeitos das falhas), VE/VA (value engineering/ value analysis, respectivamente engenharia de valor e análise de valor), dentre outras. Esses métodos e técnicas podem ser aplicados em somente um dos estágios de desenvolvimento de um novo produto ou em vários deles. Dentre os métodos que podem ser usados nos diversos estágios do processo de desenvolvimento está o QFD, detalhado a seguir por se tratar de um dos focos principais deste trabalho, bem como por ser um método estruturado que acomoda um outro conjunto de técnicas dentro dele (CHENG, 2000).

O QFD é um método voltado para o desenvolvimento de produtos e serviços cujo propósito é definir as especificações de produtos a partir do levantamento das necessidades dos clientes. A fundamentação sobre o método e sua aplicação pode ser encontrada em Akao (1990) e Cheng et al. (1995), que enfatizam as quatro dimensões do QFD: qualidade, tecnologia, custos e confiabilidade. A partir do trabalho de Akao (1990), sugiram variações do modelo original.

Mais relevantes para os propósitos desse trabalho são as aplicações diversificadas que o método proporciona para o

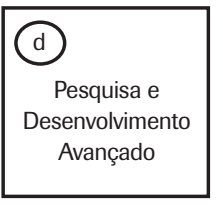

Extensão das Mudanças no Produto

Extensão das Mudanças no Processo

Novo núcleo Próxima geração Adições à família Derivativos e

de produtos de produtos de produtos melhorias
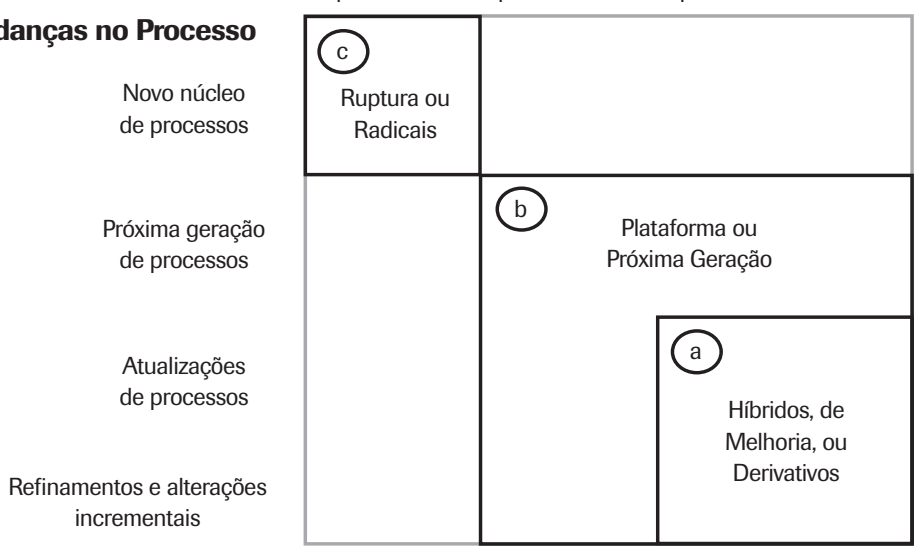

Projetos de Parceria

ou Aliança

Figura 3: Tipos de projetos de desenvolvimento (CLARK; WHEELWRIGHT, 1993).

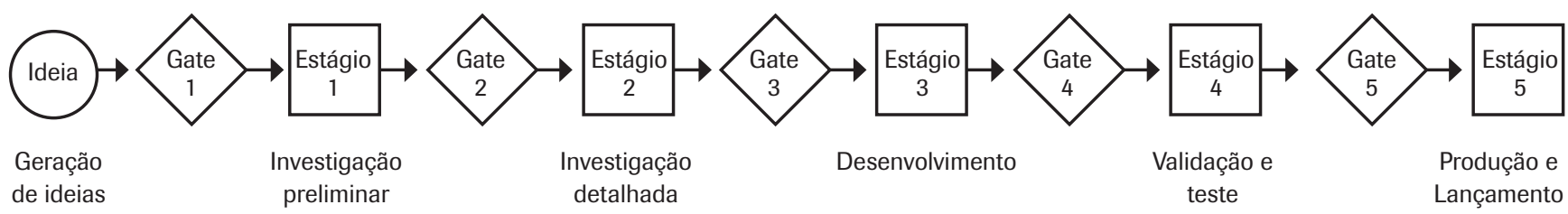

Figura 4: Stage-gate genérico (COOPER, 1993). 
desenvolvimento de produtos variados. A importância do QFD no desenvolvimento de produtos pode ser demonstrada no Quadro 8 pelas suas diversas aplicações nos mais variados setores de atividades industriais, enquanto que a Figura 5 mostra a evolução no número de artigos publicados sobre QFD em anais de eventos nacionais entre 1995 e 2003. Cabe destacar que não foram considerados artigos em periódicos nacionais pois a quantidade é muito limitada.

Uma revisão bibliográfica sobre o uso do QFD, com base em aproximadamente 300 artigos em periódicos pode ser vista em Dias e Miguel (2001). Outra referência mais atualizada sobre o uso do QFD pode ser vista em Chan e Wu (2002), baseada na revisão de mais de 650 referências sobre o método e classificação dos trabalhos segundo alguns critérios.

A literatura também aponta diversos benefícios na adoção do QFD. O Quadro 9 apresenta uma síntese de benefícios tangíveis e intangíveis a partir de consulta à literatura.

A partir dos benefícios no uso do QFD, advindos da literatura, destaca-se então a importância da utilização do método. No entanto, apesar dos benefícios decorrentes da sua aplicação, um aspecto importante a ser verificado na literatura é a inserção do método em processos de desenvolvimento estruturados de produto. Alguns trabalhos que exploram a utilização do método e em que momento deve ser aplicado nos estágios de desenvolvimento foram investigados (e.g. COOPER, 1993; APQP, 1997, GUNASEKARAN, 1998; PETERS et al., 1999). No entanto, existe uma aparente lacuna na literatura sobre a aplicação do QFD, relacionada a como o método deve ser aplicado no processo de desenvolvimento de produto, isto é, em que estágios deve ser usado, com que intensidade, como suas atividades devem ser distribuídas, dentre outros aspectos. Publicações mais recentes (e.g. ROZENFELD et al., 2006) sugerem, em linhas gerais, a

Quadro 8: Algumas aplicações típicas do QFD no Brasil.

\begin{tabular}{ll}
\hline \multicolumn{1}{c}{ Setor Industrial } & \multicolumn{1}{c}{ Autor(es) } \\
\hline Alimentos & Ormanese et al. (1996); Sarantopoulos et al. (1996); Guedes et al. (1999); \\
& Paiva e Cheng (2001); Polignano e Castanheira (2003) \\
Automotivo & Rosati (1997); Nogueira et al. (1999); Santiago e Cheng (1999) \\
Construção civil & Londe e Cosenza (1997); Bacelar et al. (2001) \\
Serviços & Danilevicz e Ribeiro (1998); Passeto et al. (1999); Moysés e Turrioni (2000); Bratz et al. (2001); \\
& Duarte et al. (2001) \\
Software & Sonda et al. (2000) \\
\hline
\end{tabular}

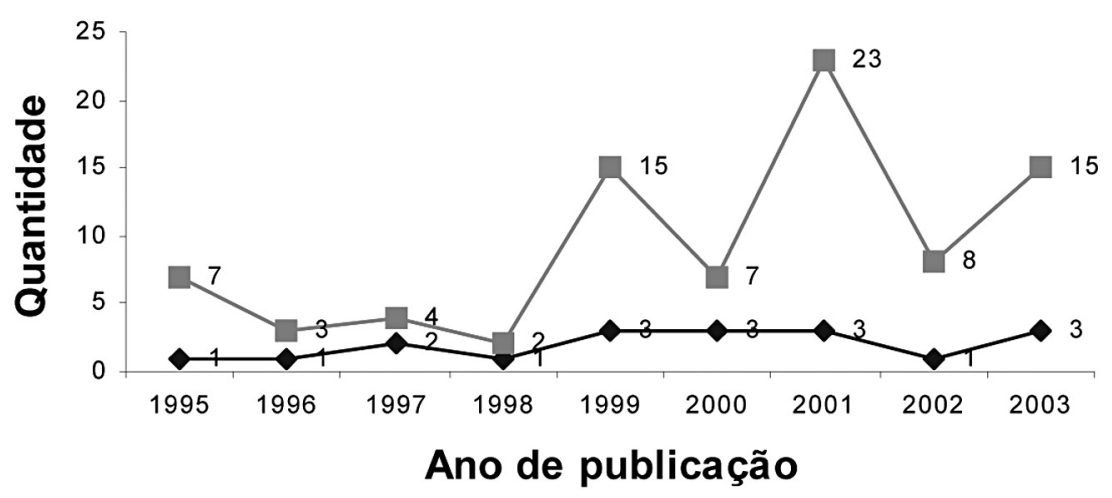

no de anais - - artigos publicados

Figura 5: Publicações sobre QFD (SASSI, 2005). 
aplicação do QFD nas fases de um modelo de referência para desenvolvimento de um novo produto, mas não fornece uma abordagem detalhada de uso do QFD nestas fases. Assim, considerando a literatura disponível, pode-se identificar uma lacuna importante para a pesquisa na área. Essa lacuna, de certa forma, justifica a condução da pesquisa-ação proposta, cujos resultados são apresentados a seguir.

\section{RESULTADOS}

Como mencionado anteriormente, a estruturação na empresa estudada compreendia três iniciativas distintas caracterizadas pelas práticas organizacionais ilustradas na
Figura 6, a saber: a gestão do portfólio de desenvolvimento de novos produtos, a reestruturação do processo para desenvolver novos produtos e a implementação de um método de suporte a este processo (o QFD). Nesse sentido, os resultados decorrentes da implantação são divididos em duas partes: a estruturação do desenvolvimento de novos produtos e a introdução do QFD, sendo que a parte relativa à gestão de portfólio está fora do escopo do presente trabalho, e sua abordagem metodológica é diferente (MIGUEL, 2008).

Numa breve explanação da Figura 6, a parte esquerda da figura ilustra a gestão de portfólio, consistindo dos seguintes conjuntos: ideias a serem desenvolvidas (podendo tornar-se projetos), projetos "em espera" (aguardando recursos para serem desenvolvidos, conforme a prioridade estratégica),

Quadro 9: Benefícios no uso do QFD.

\begin{tabular}{ll}
\hline \multicolumn{1}{c}{ Benefícios } & \multicolumn{1}{c}{ Referências } \\
\hline Tangíveis e Intangíveis & Kathawala e Motwani (1994); Govers (1996); Bouchereau \& Rowlands (2000a, b); Cristiano et al. (2000); \\
& Martins e Aspinwall (2001) \\
Tangíveis & Kim et al. (1997); Sim e Curatola (1999); Karsak et al. (2002) \\
Intangíveis & Hauser e Clausing (1988); Ross (1988); Lu et al., (1994); Lu e Kuei, (1995); Bergquist e Abeysekera (1996); \\
& Han et al. (1998); Bier e Cornesky (2001); Govers (2001); Olhager e West (2002); Parkin et al. (2002); Cheng \\
& (2003); Lee e Lo (2003); Gerst (2004); Ginn e Zairi (2005) \\
\hline
\end{tabular}
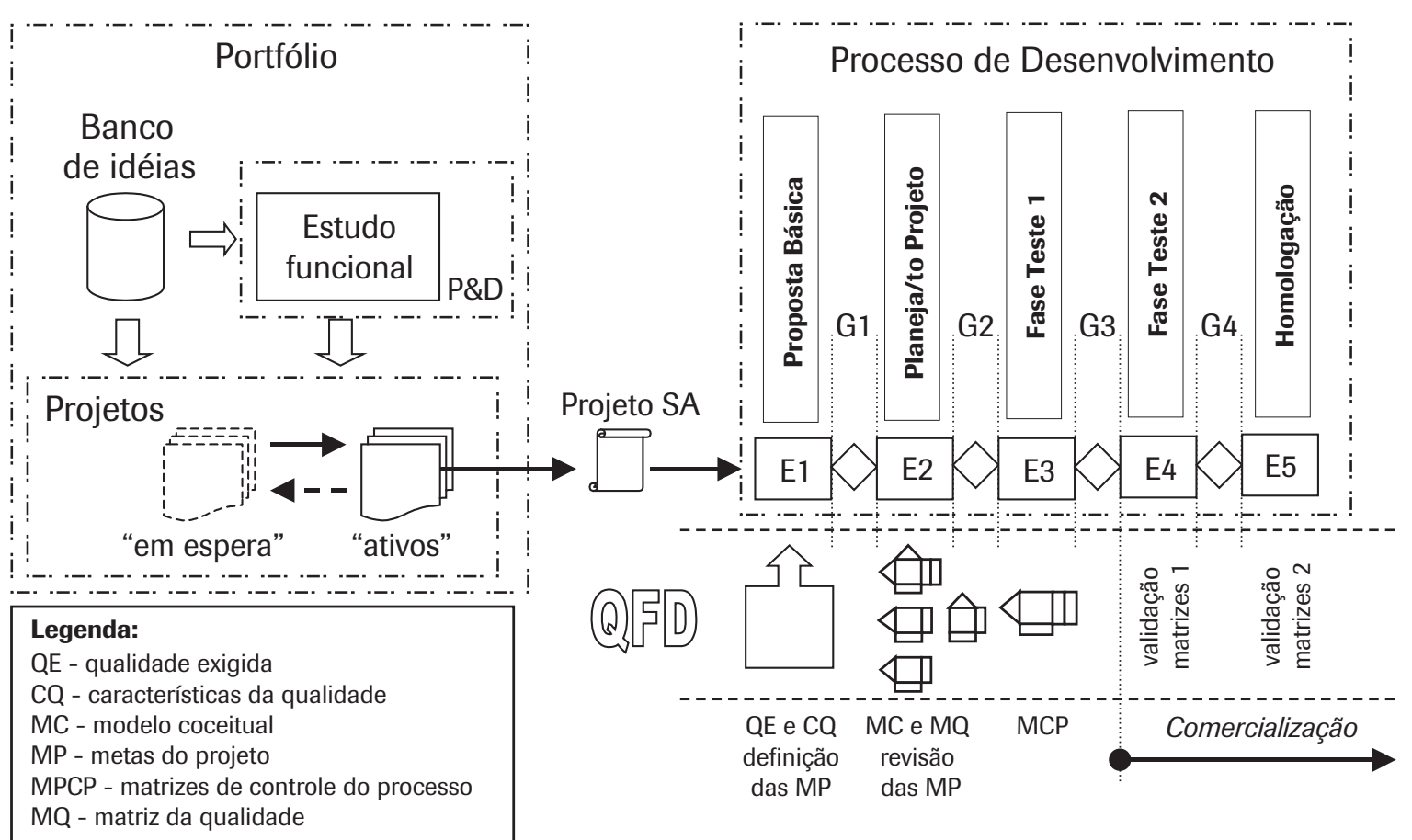

Figura 6: Implantação na empresa estudada. 
e projetos "ativos" (sendo desenvolvidos correntemente e simultaneamente). A parte do meio da Figura 6 ilustra um projeto individual (genericamente denominado de "SA"), que está na carteira ativa de desenvolvimento. Este projeto adentra no processo de desenvolvimento dividido em estágios e gates (mostrados na parte superior direita da Figura 6). Na parte inferior direita são representadas as atividades relativas à aplicação do QFD, ilustrando sua inserção em cada estágio do processo de desenvolvimento do novo produto. Como citado anteriormente, a gestão de portfólio não é analisada no presente trabalho, mas as outras iniciativas são apresentadas a seguir.

\section{desenvolvimento de produtos é um campo vasto de conhecimento visto sob diferentes perspectivas, com inúmeras atividades estruturadas nos níveis estratégico e organizacional.}

\subsection{Restruturação do processo de desenvolvimento}

Basicamente, a reestruturação do processo de desenvolvimento compreende três etapas principais:

- Diagnóstico do desenvolvimento de produto, antes da restruturação;

- Proposta de um novo processo de desenvolvimento de produtos;

- Proposta de inserção do QFD no novo processo de desenvolvimento.

No passado, a empresa em estudo desenvolvia produtos, com procedimentos definidos a partir do requisito " 4.4 Controle de Projeto” da norma ISO 9001, versão de 1994, com o desenvolvimento de novos produtos centrado na área de P\&D. A empresa seguia um fluxograma que determinava uma sequência básica para desenvolvimento de um novo produto, mas que apresentava algumas dificuldades na execução dos projetos, relacionadas a(os):

- Dados de entrada: geralmente dispersos na empresa, sendo comum que houvesse informações contraditórias sobre os dados, além de não haver um canal de comunicação eficaz que garantisse que estes seriam plenamente utilizados ao longo do processo de desenvolvimento do novo produto. Uma situação que era sempre citada, era a de um projeto que já tinha alcançado a fase final, com amostras de produção e resultados favoráveis das especificações e o cliente informava que havia faltado uma dada especificação do produto.

- Transformação das necessidades do mercado em especi- ficações do produto: não existia um mecanismo formal para que os dados e informações advindos do mercado fossem traduzidos em especificações. Geralmente, cada responsável pelo desenvolvimento do novo produto estabelecia seus próprios critérios para que isso fosse feito, o que causava uma variação nos resultados de desenvolvimento em função de falta de padronização.

- Planejamento inicial antes do desenvolvimento propriamente dito: faltava a definição de um plano de atividades, não somente relativo aos parâmetros técnicos, mas também quanto ao planejamento de prazos, recursos, e de custos. A tendência que havia era de já partir para a realização de testes na linha de produção, sem que houvesse um planejamento experimental adequado.

- Fases do desenvolvimento: apesar do fluxograma considerar algumas fases, estas não eram bem definidas, bem como não era evidente quais eram os critérios para que o desenvolvimento do produto evoluísse ao longo do tempo e progredisse por cada uma dessas fases. Assim, o projeto seguia de uma forma descontínua e variava (em termos de tempo e de resultados) conforme quem da área de $\mathrm{P} \& \mathrm{D}$ era responsável pelo projeto do novo produto.

- Centralização do desenvolvimento em somente uma área funcional (P\&D): o desenvolvimento cabia somente ao pessoal da área de $\mathrm{P} \& \mathrm{D}$, com baixo nível de comprometimento e apoio das outras áreas funcionais. Isso trazia limitações para a realização dos testes necessários ao desenvolvimento do produto, principalmente relativas ao compartilhamento de informações entre as áreas envolvidas e de know how sobre os processos de manufatura, dificuldades para resgate e utilização da experiência acumulada com outros projetos, bem como acesso às lições aprendidas com os desenvolvimentos anteriores.

Assim, a partir dos pontos listados acima, foi feita uma proposta visando reestruturar a maneira pela qual os produtos vinham sendo desenvolvidos. Esta proposta foi centrada na gestão por processos, vindo também a atender os requisitos da nova versão da ISO 9001: 2000, compreendendo a definição das seguintes partes:

- Estrutura organizacional de trabalho com definição de responsabilidades: primeiramente foi estabelecido um comitê de projetos, como sendo a instância máxima de decisão e de gestão dos projetos de novos produtos da empresa, formado por gerentes funcionais (marketing, $\mathrm{P} \& \mathrm{D}$, comercial, qualidade e produção) e pelo diretor geral da empresa. Este comitê é quem analisa todas as ideias 
propostas na empresa, realizando reuniões de portfólio, avalia os projetos individuais nos gates, define quem será o gerente de projetos, e aprova a equipe multi-funcional. A estrutura organizacional para gestão de projetos na empresa é estabelecida em um formato matricial peso leve, conforme Clark e Wheelwright (1993), com equipes temporárias, compostas por pessoas das áreas envolvidas com o desenvolvimento do novo produto. Um membro da equipe é designado como gerente do projeto, podendo vir de qualquer área funcional da organização e assumir uma ou mais gerências de projetos de desenvolvimento simultaneamente.

- Definição de estágios e gates: foi adotado o modelo de stage-gate, similar ao de Cooper (1993), composto por cinco estágios: Proposta Básica, Planejamento do Projeto, Desenvolvimento - Fase Teste 1, Desenvolvimento - Fase Teste 2 e Homologação. Os estágios são detalhados mais à frente, sendo que os gates consideram três tipos básicos de decisão: "aprovado" (segue para o estágio seguinte), "necessita de mais informações" (permanece no estágio atual), e "reprovado" (o projeto é arquivado - suspenso ou cancelado). A validação de cada estágio nos gates é conduzida pelo comitê de projetos.

- Elaboração da documentação para o sistema: a principal peça na documentação do sistema foi a elaboração de um manual de projetos, um documento de primeiro nível, estabelecendo os seguintes pontos básicos: objetivos, estrutura organizacional (adotando o gerenciamento de projetos da empresa, segundo o PMBOK do PMI, 2000), ciclo de vida do projeto (sequência de decisões e procedimentos a serem seguidos desde o surgimento da idéia de um novo produto até o seu fornecimento em escala comercial); definição de responsabilidade e autoridade para os participantes; documentos e formulários do sistema; e um glossário com os principais termos e expressões do sistema de desenvolvimento de novos produtos. Além do manual de projetos, foi também desenvolvida a documentação a ser usada nos gates.

O Quadro 10 mostra uma comparação entre o desenvolvimento de produtos anterior e a proposta implantada.

Como mostra o Quadro 10, houve uma mudança na maneira pela qual o desenvolvimento de produto era conduzido na empresa investigada. Essa alteração envolveu tanto o nível estratégico quanto o nível operacional, com relação à condução dos projetos no desenvolvimento e organização da equipe de desenvolvimento, destacado como ponto relevante por Lowe e Ridgway (2000). O desenvolvimento de novos produtos passou a ser melhor estruturado, com maior ênfase na fase de planejamento. Como um consultor sênior de P\&D costumava afirmar: "a realidade anterior era a de sair fazendo o produto", ou seja, partia-se de imediato para os testes de produção sem nenhuma análise cuidadosa em relação ao consumo de recursos, mercado, dados de entrada, etc. No

Quadro 10: PDP - Antes e após a estruturação.

\begin{tabular}{|c|c|c|}
\hline & Antes & Após \\
\hline $\begin{array}{l}\text { Decisões de Desenvolvimento } \\
\text { (o que desenvolver) }\end{array}$ & $\begin{array}{l}\text { Prioridades de acordo com a área de } \\
\text { P\&D; critérios próprios da gerência }\end{array}$ & $\begin{array}{l}\text { Decisões baseadas na gestão do portfolio; critérios: } \\
\text { alinhamento estratégico, tecnológico, grau de } \\
\text { dificuldade, retorno do investimento (ver MIGUEL, 2008) }\end{array}$ \\
\hline $\begin{array}{l}\text { Fases de Desenvolvimento } \\
\text { (como desenvolver) }\end{array}$ & $\begin{array}{l}\text { Não muito bem definido; pouca } \\
\text { simultaneidade }\end{array}$ & $\begin{array}{l}\text { Bem definido; alguma simultaneidade até certa } \\
\text { extensão (principalmente na Fase Teste } 1 \text { e Fase } \\
\text { Teste 2, respectivamente desenvolvimento do } \\
\text { conceito e do processo) }\end{array}$ \\
\hline $\begin{array}{l}\text { Organização do grupo de } \\
\text { desenvolvimento (quem } \\
\text { desenvolve) }\end{array}$ & $\begin{array}{l}\text { Praticamente não eram utilizadas } \\
\text { equipes de trabalho }\end{array}$ & $\begin{array}{l}\text { Times multi-funcionais com um gerente } \\
\text { designado para cada projeto }\end{array}$ \\
\hline $\begin{array}{l}\text { Envolvimento de outras áreas no } \\
\text { desenvolvimento de produto }\end{array}$ & $\begin{array}{l}\text { Centralizado na área de P\&D com } \\
\text { pouco envolvimento da área de } \\
\text { processos }\end{array}$ & $\begin{array}{l}\text { Praticamente todas as áreas funcionais envolvidas com } \\
\text { o desenvolvimento (P\&D, engenharia de processos, } \\
\text { produção, marketing, vendas, etc.) }\end{array}$ \\
\hline $\begin{array}{l}\text { Organização e gestão } \\
\text { do projeto }\end{array}$ & Estrutura e gestão funcional & $\begin{array}{l}\text { Estrutura matricial leve; baseado nos princípios do } \\
\text { PMBoK (PMI, 2000) }\end{array}$ \\
\hline Atividades de desenvolvimento & Baseada em um fluxograma simples & Baseada em um processo estruturado com fases e gates \\
\hline $\begin{array}{l}\text { Métodos de suporte no } \\
\text { desenvolvimento de novos } \\
\text { produtos }\end{array}$ & Nenhum & QFD \\
\hline
\end{tabular}


entanto, embora a estruturação do processo de desenvolvimento tenha sido relevante, coube ainda a introdução de um método que pudesse dar suporte à condução de cada projeto individualmente. Assim, foi introduzido o QFD, cujos resultados são apresentados a seguir.

\subsection{Implementação do QFD}

O Quadro 11 apresenta uma síntese dos principais marcos históricos da implementação do QFD, visando ilustrar sua implementação gradativa na empresa, em quatro fases distintas: projeto piloto, $1^{\circ}$ conjunto com 5 projetos, $2^{\circ}$ conjunto com 3 projetos e 3 - conjunto com 4 projetos (Figura 7). A definição destas fases foi baseada na experiência bem sucedida da implementação do QFD na Sadia, descrita por Cheng e Satantopoulos (1995). A divisão por fases objetivou organizar melhor a implementação, propondo um efeito multiplicador gradativo. Essa introdução mais gradativa visava possibilitar que a empresa e integrantes das equipes adquirissem um maior conhecimento sobre o QFD, utilizando-o em projetos de natureza diferente, mas não necessariamente mais complexos (embora alguns dos projetos das fases 3 e 4 fossem projetos do tipo plataforma e, portanto, com maior grau de introdução de inovações). Além disso, houve aumento na quantidade de colaboradores da empresa que participavam das equipes e estes vinham tendo maior familiaridade com o QFD. $\mathrm{Na}$ sequência, aspectos relativos à implementação, com base na literatura, também são relatados.
Fase 1) Projeto Piloto - Introdução do QFD na Empresa

Inicialmente, foi conduzido um projeto piloto para que a empresa pudesse aprender sobre o uso do método, além de demonstrar resultados de sua aplicação para a alta gerência. Os resultados e descrição mais detalhados sobre esse projeto estão em Miguel et al. (2003). Um ponto importante para qualquer implantação é a avaliação dos seus resultados em termos de recursos consumidos, mostrados no Quadro 12. Os dados desse quadro foram levantadas por meio dos registros do pesquisador e atas de reunião, também elaboradas pelo autor.

A Figura 8 mostra a redução no índice de devolução do produto após a introdução do QFD, levantado nos registros de qualidade na organização (é importante destacar que esse produto usado como piloto era existente). Foram levantadas nos relatórios de devolução as quantidades devolvidas e as razões da devolução. Considerou-se, portanto, somente as devoluções decorrentes de problemas relativos ao projeto (especificações) e não de outra natureza.

\section{Fase 2) Multiplicação do QFD para cinco projetos de novos produtos}

A Figura 9 ilustra o processo difusão para 4 projetos de novos produtos e 1 projeto de melhoria de produto utilizando o QFD. Os membros da equipe que participaram no projeto piloto atuaram como multiplicadores do conhecimento em cada novo projeto.

Um ponto importante nessa fase, foram as avaliações do andamento de cada um dos projetos de novo produto. Assim,

Quadro 11: Marcos na implementação do QFD.

\begin{tabular}{ll}
\hline \multicolumn{1}{c}{ Data } & \multicolumn{1}{c}{ Descrição } \\
\hline Agosto/Ano 1 & Primeiro contato da empresa demonstrando interesse na utilização do QFD \\
Outubro/Ano 1 & Primeira reunião na empresa para discussão da possível implantação \\
Fevereiro/Ano 2 & Segunda reunião para apresentação de proposta de implantação do QFD \\
Abril/Ano 2 & Nova reunião com o Comitê de Projetos para discussão da proposta \\
Maio/Ano 2 & Início do projeto piloto \\
Fevereiro/Ano 3 & Autoavaliação sobre o conhecimento do QFD (membros da equipe do piloto) \\
Abril/Ano 3 & Início da aplicação do QFD para 5 novos projetos \\
Agosto/Ano 3 & Treinamento sobre QFD (reciclagem e novos membros de equipe de projeto) \\
Março/Ano 4 & Apresentação da evolução do QFD nos projetos para a diretoria \\
Outubro/Ano 4 & Início da aplicação do QFD para 3 novos projetos \\
Março/Ano 5 & Minitreinamento sobre os princípios do QFD e sua aplicação na empresa \\
Maio/Ano 5 & Início da aplicação do QFD para 4 novos projetos \\
Outubro/Ano 5 & Treinamento sobre o conceito do QFD e resultados nos projetos da empresa \\
Nov./Ano 5 & Encerramento da participação do pesquisador na empresa \\
\hline
\end{tabular}




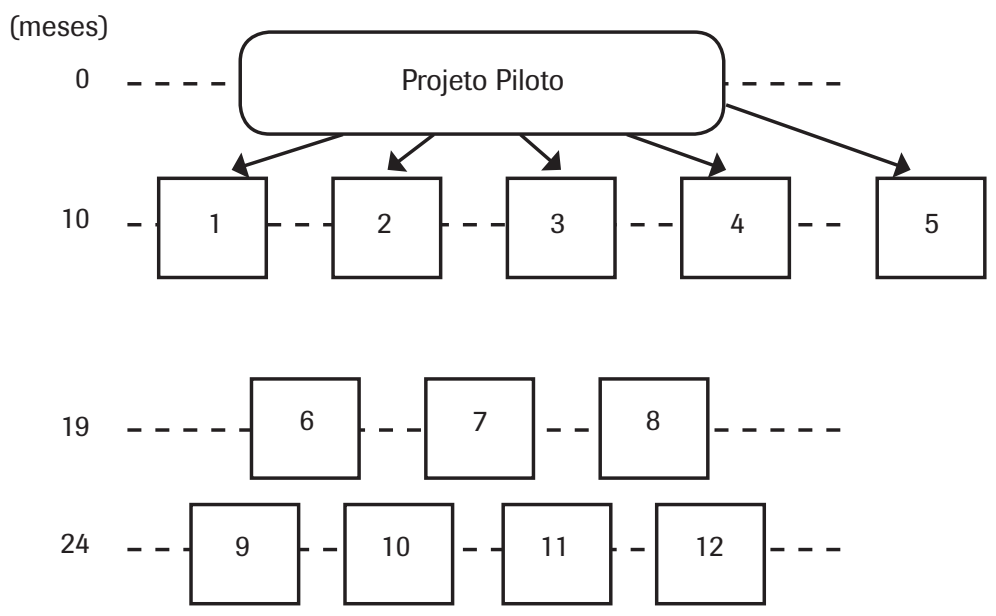

Figura 7: Multiplicação do QFD.

Quadro 12: Horas despendidas no projeto piloto.

\begin{tabular}{lc}
\hline \multicolumn{1}{c}{ Indicador } & Resultado \\
\hline Número médio de participantes nas reuniões & 8 \\
Quantidade de horas por reunião (média) & 4,5 horas \\
Total de reuniões de trabalho (exclui reuniões de avaliação e elaboração do manual do QFD) & 37 \\
Quantidade total de horas de reunião de trabalho (horas reais, extraídas das atas de reunião) & 169,5 horas \\
Estimativa de tempo com follow up para a Diretoria (duas apresentações) & 4,0 horas \\
Estimativa de tempo com experimentos (testes estatísticos e medições de laboratório) & 35,5 horas \\
Estimativa de tempo com visitas a 5 clientes (levantamento das qualidades exigidas e atribuição & 24 horas \\
do grau de importância) e à Sadia & 14 horas \\
Quantidade de tempo com as avaliações da implantação & 79 horas \\
Estimativa de tempo para elaboração do manual de QFD & 326 horas \\
Quantidade total de horas despendidas com o projeto piloto &
\end{tabular}

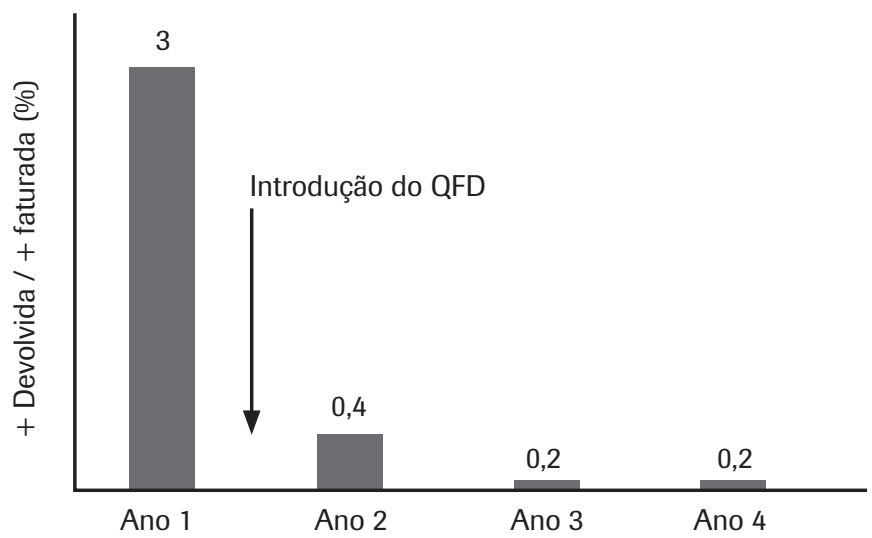

Figura 8: Devoluções - projeto piloto. 
foi desenvolvido um conjunto de atividades básicas do QFD, utilizado periodicamente para a avaliação de seu uso. A planilha utilizada é apresentada na Figura 10. Nas colunas são mostradas as diversas atividades para a aplicação do QFD e nas linhas cada projeto sendo desenvolvido.

Para avaliar o resultado da aplicação do método nesses projetos, foi estabelecida uma avaliação baseada em alguns critérios com atribuições de valores baseados em uma escala Likert (de 1 - péssimo a 5 - excelente). A Tabela 1 mostra um dos resultados dessa avaliação (feita pelo pesquisador em conjunto com os membros das equipes), que eram enviados para o comitê de projetos, gerando correções na implementação. Além da referida tabela, um relatório incluía uma avaliação individual de cada um dos projetos.

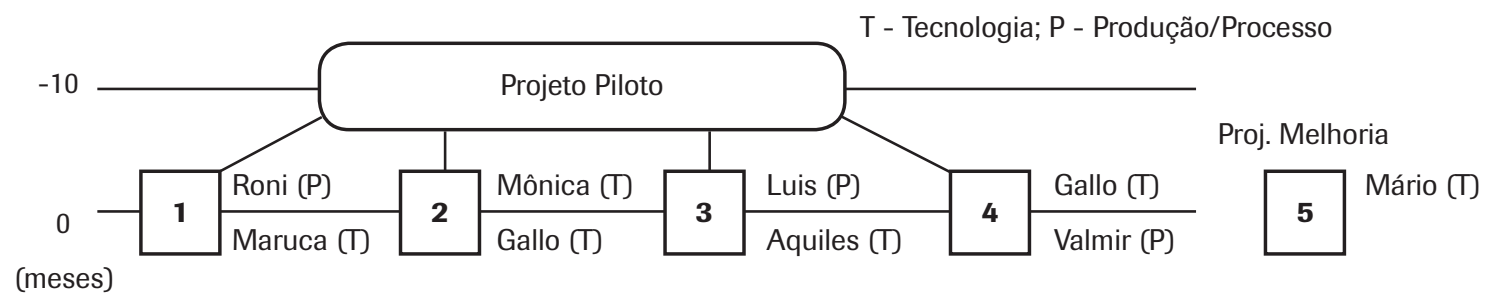

Figura 9: Difusão do QFD para outros projetos.

\begin{tabular}{|c|c|c|c|c|c|c|c|c|c|c|c|c|c|c|c|c|c|c|c|c|c|c|c|c|c|c|c|c|c|}
\hline & & & \multicolumn{12}{|c|}{ Matriz da qualidade } & \multicolumn{4}{|c|}{$\begin{array}{l}\text { Matriz de } \\
\text { processos }\end{array}$} & \multicolumn{5}{|c|}{ Matriz de aditivos } & \multicolumn{5}{|c|}{$\begin{array}{c}\text { Matriz de } \\
\text { matéria-prima }\end{array}$} & \multirow[b]{2}{*}{ 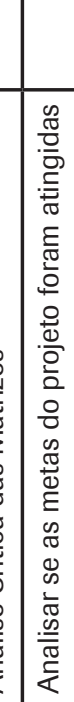 } \\
\hline Projeto & 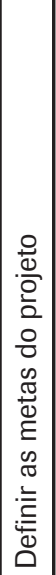 & 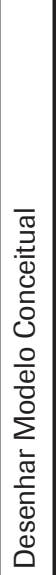 & 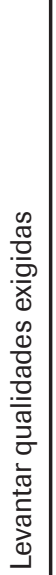 & 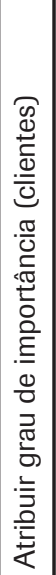 & 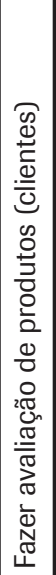 & 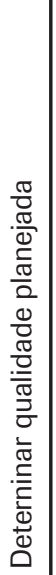 & 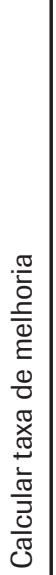 & 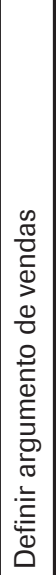 & 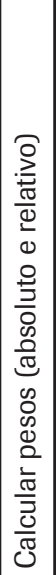 & 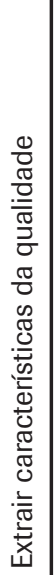 & 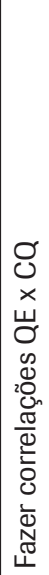 & 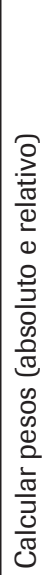 & 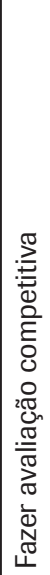 & 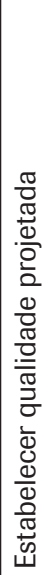 & 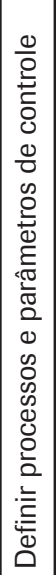 & 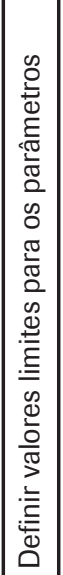 & 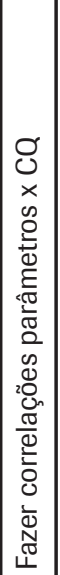 & 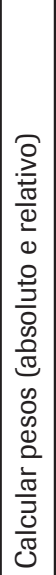 & 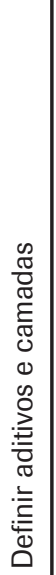 & 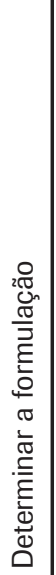 & 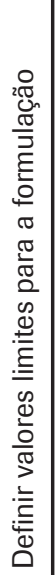 & 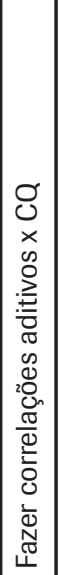 & 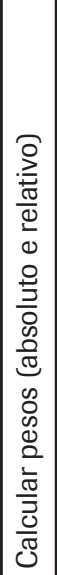 & 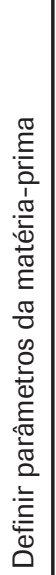 & 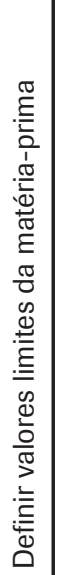 & 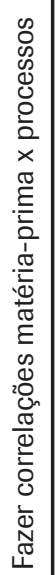 & 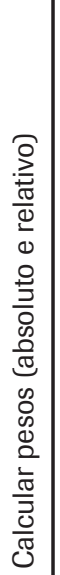 & 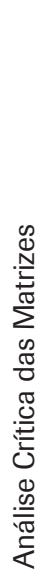 & \\
\hline 1 & & & & & & & & & & & & & & & & & & & & & & & & & & & & & \\
\hline 2 & & & & & & & & & & & & & & & & & & & & & & & & & & & & & \\
\hline 3 & & & & & & & & & & & & & & & & & & & & & & & & & & & & & \\
\hline 4 & & & & & & & & & & & & & & & & & & & & & & & & & & & & & \\
\hline 5 & & & & & & & & & & & & & & & & & & & & & & & & & & & & & \\
\hline
\end{tabular}

Realizado Realizado em parte

Figura 10: Monitoramento dos projetos conforme as etapas do QFD. 
A partir da experiência com esses 5 projetos, foi então desenvolvido um cronograma geral, mostrado na Figura 11, para as atividades de aplicação do QFD, de forma mais direcionada para a realidade da empresa. É claro que o período para cada atividade poderia variar, dependendo da tipologia do projeto (por exemplo, se fosse do tipo plataforma ou derivativo), mas esse cronograma seria um ponto de partida no planejamento inicial para a elaboração da proposta básica do projeto.

\section{Fase 3) Multiplicação do QFD para três projetos de novos produtos}

A partir da multiplicação gradativa do QFD para outros

Tabela 1: Avaliação do QFD nos projetos.

\begin{tabular}{|c|c|c|c|c|c|c|}
\hline Projeto & $\begin{array}{c}\text { Índice } \\
\text { de reuniões }\end{array}$ & $\begin{array}{c}\text { № } \\
\text { de matrizes }\end{array}$ & $\begin{array}{c}\text { Fase } \\
\text { do Projeto }\end{array}$ & $\begin{array}{l}\text { Andamento do } \\
\text { QFD no projeto }\end{array}$ & $\begin{array}{c}\text { Falta para } \\
\text { concluir o QFD }\end{array}$ & $\begin{array}{l}\text { Benefícios do uso } \\
\text { do QFD no projeto }\end{array}$ \\
\hline 1 & 0,60 & 4 & Estágio 2 & 3 & 3 & 4 \\
\hline 2 & 0,40 & 6 & F.Teste 2 & 4 & 4 & 3 \\
\hline 3 & 0,64 & 5 & F.Teste 1 & 3 & 3 & 2 \\
\hline 4 & 0,2 & 5 & Estágio 2 & 2 & 2 & 1 \\
\hline 5 & 0,04 & indefinido & s/ informação & 1 & 1 & 1 \\
\hline
\end{tabular}

Notas: 1. Índice de reuniões: número de reuniões ocorridas com acompanhamento do pesquisador dividido pelo número de reuniões previstas (25);

2. Fase do projeto: classificação atribuída no início de uso do QFD no projeto e de acordo com o novo processo de desenvolvimento de novos produtos da empresa

3. Projeto 5: sse projeto não vinha utilizando o QFD.

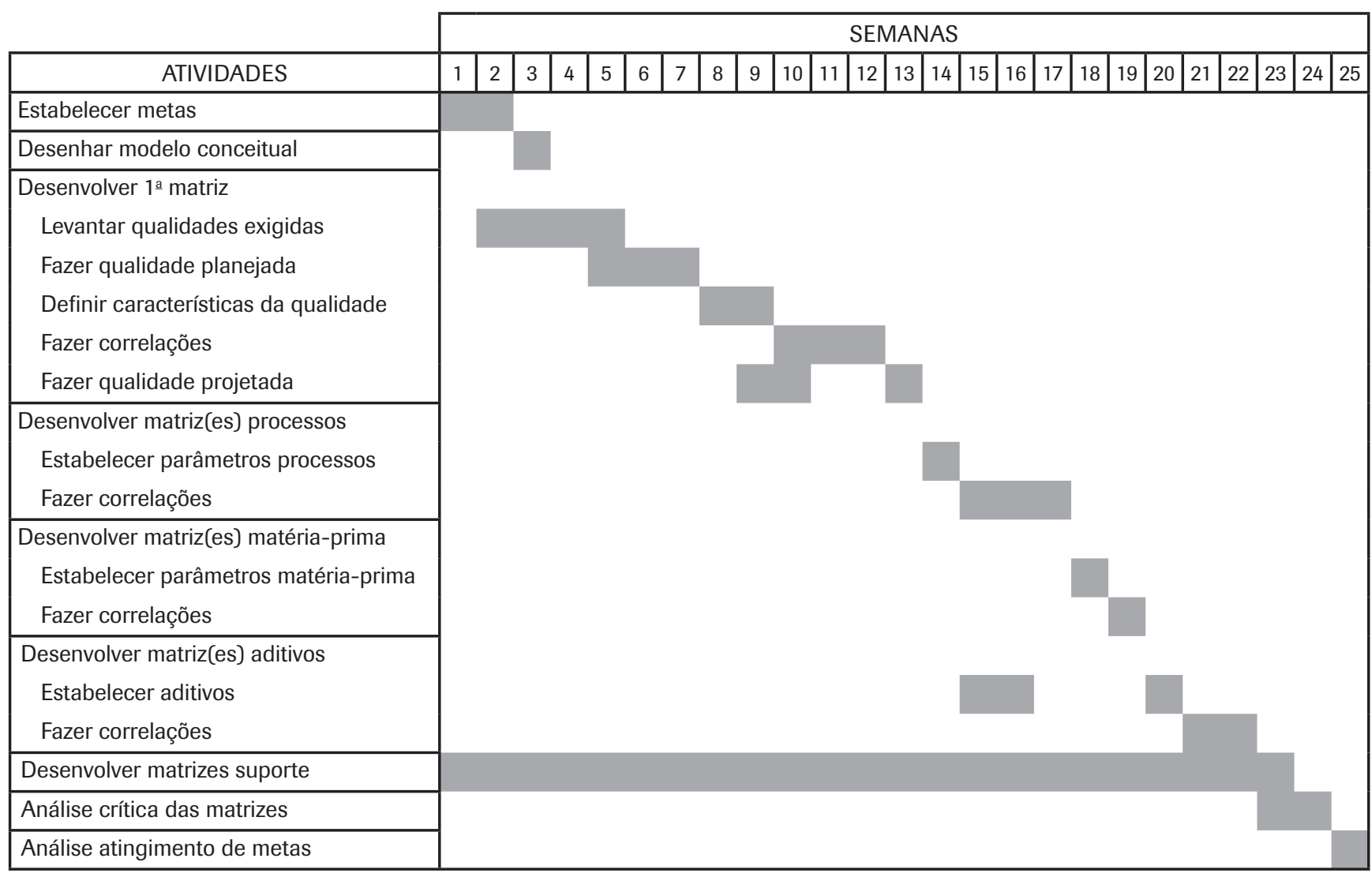

Figura 11: Cronograma genérico para as etapas do QFD. 
projetos, o método passou a ser aplicado em três novos produtos. Um ponto importante nessa fase foi a realização de uma reunião decisiva com o diretor geral da empresa, para avaliar a utilização do QFD e seus benefícios na condução dos projetos na organização. A partir dessa reunião, alguns pontos relevantes foram levantados, destacando-se ainda a necessidade de definir mais claramente como as atividades do QFD deveriam inserir-se no processo de desenvolvimento de produtos, como já havia sido identificado na teoria sobre a sua aplicação. Assim, esta foi uma ação a ser priori-

\section{Acestruturação do PDP trouxe maior}

\section{sua performance e reduzindo o ciclo de desenvolvimento de produto de dois para um ano.}

Fase 4) Multiplicação do QFD para quatro projetos de novos produtos

Nessa fase, de maior maturidade na utilização do QFD, destacam-se a identificação e implementação de boas práticas no uso do método. O Quadro 13 apresenta algumas das boas práticas identificadas nos diversos projetos de desenvolvimento de novos produtos.

\subsection{Contribuições do trabalho}

As boas práticas de uso do método que foram identificadas no presente estudo podem ser consideradas como uma contribuição à teoria sobre o QFD, tanto no aspecto mais específico como no caso da elaboração das matrizes, quanto no sentido mais amplo de transferência de informações para outras áreas envolvidas com o desenvolvimento do novo produto. Nesse sentido, o trabalho realizado contribuiu para a redução das dificulda-

zada, elaborando-se uma proposta de como essas atividades deveriam ser distribuídas nos estágios de desenvolvimento, mostrada na Figura 12, considerando, para desenvolvimento dessa proposta, os trabalhos de Clark e Wheelwright (1993), bem como os princípios do APQP (1997).

É importante destacar que essa proposta foi inserida no manual de projetos de desenvolvimentos de novos produtos da empresa, de forma a considerar, continuamente, a distribuição das atividades do QFD no seu processo de desenvolvimento de produtos. Além disso, parte da documentação gerada na condução do projeto também deveria ser utilizada como critério de análise dos projetos nos gates. des de elaboração das matrizes, relativas à interpretação da "voz do cliente" (identificado por CHAN; WU, 2005) e priorização das características da qualidade (apontado por KARSAK, 2004).

Como contribuição complementar à teoria, a adoção do QFD na forma mais completa de Akao (1990), com pelo menos dois desdobramentos (qualidade e tecnologia), mostrou-se exequível, contribuindo para validar as propostas de Cheng e Sarantopoulos (1995) e Cheng et al. (1995). Uma das principais limitações encontradas na literatura (e.g. CRISTIANO et al., 2000; MARTINS; ASPINWALL, 2001), sobre o uso do método, é a utilização somente do desdobramento

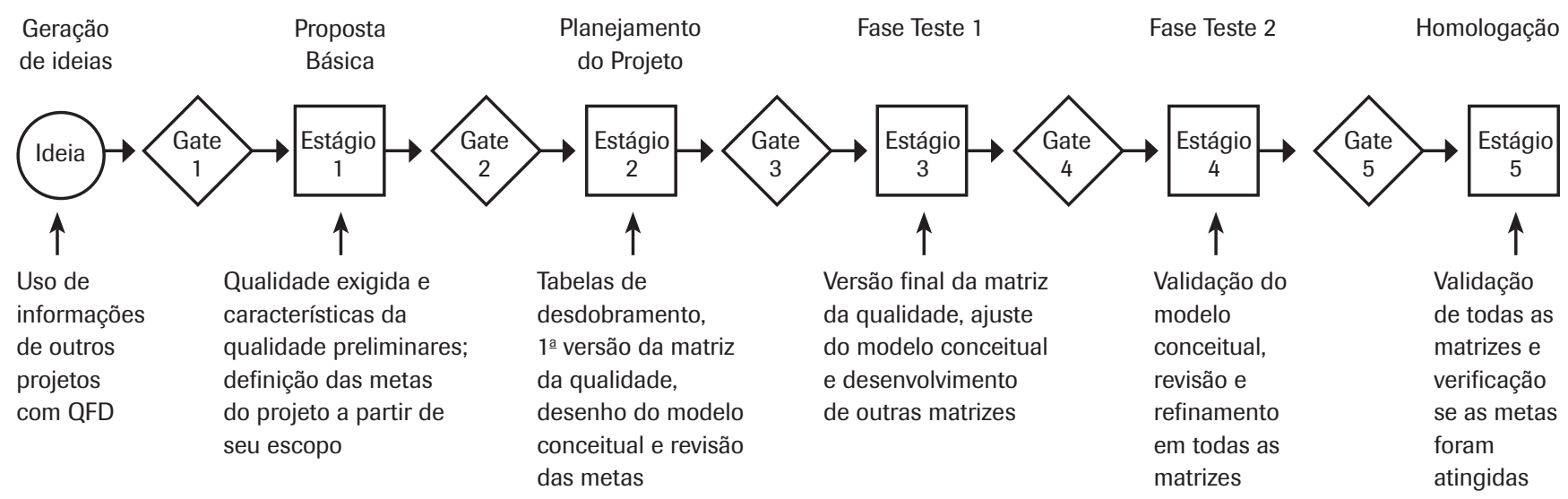

Figura 12: QFD no PDP. 
da qualidade. Assim, o presente estudo vem empiricamente contribuir com uma maior extensão empírica na aplicação do método, complementando os trabalhos citados anteriormente. Embora com as devidas limitações, considera-se que a descrição metodológica do trabalho possibilita sua replicação, com os desafios inerentes à natureza desse tipo de investigação (CHECKLAND; HOLWELL, 1998).

Finalmente, podem-se citar algumas contribuições para a empresa estudada, advindas da implantação. Essas contribuições são importantes face à natureza da abordagem da pesquisa-ação, em termos de alinhamento da teoria vigente com o campo empírico, na busca de solução para um determinado desafio organizacional. Assim, a reestruturação do PDP trouxe uma maior capacitação da empresa e de seus funcionários no que se refere à condução das atividades de desenvolvimento, tão importantes face à competição atual. A maior parte dos projetos completados durante o tempo em que o estudo foi conduzido resultou em melhoria de performance no mercado e redução de devoluções e reclamações (respectivamente nas Figuras 8 e 13). Um outro benefício que pode ser citado foi a redução no ciclo de desenvolvimento de produto da empresa de dois para um ano.

Quadro 13: Boas práticas no uso do QFD.

\begin{tabular}{ll}
\hline \multicolumn{1}{c}{ Boa Prática } & \multicolumn{1}{c}{ Descrição Resumida } \\
\hline Interação com os clientes & $\begin{array}{l}\text { Abordagem utilizada no levantamento das qualidades exigidas junto ao cliente, resultando em maior } \\
\text { precisão na definição destas, com consequente redução nas reclamações dos clientes no re-projeto } \\
\text { de um produto existente (Figura 13) }\end{array}$ \\
$\begin{array}{l}\text { Informações nas relações } \\
\text { nas matrizes }\end{array}$ & $\begin{array}{l}\text { Inclusão de comentários nas matrizes (planilha do Excel) relativos às decisões de relação de } \\
\text { intensidade, resultando em um histórico do desenvolvimento, possível de ser rastreado e usado em } \\
\text { outros projetos de novos produtos }\end{array}$ \\
$\begin{array}{l}\text { Transferência de informação } \\
\text { do QFD para a documentação }\end{array}$ & $\begin{array}{l}\text { Transferência das informações advindas do QFD para as folhas de especificações, procedimentos de } \\
\text { produção, etc., resultando em uma das contribuições do QFD, além das matrizes }\end{array}$ \\
$\begin{array}{l}\text { Utilização da matriz de } \\
\text { decisão }\end{array}$ & $\begin{array}{l}\text { Uso de matriz de decisão, baseado na seleção de conceitos de Pugh (1991) para escolha da melhor } \\
\text { formulação (receita), resultando em uma ferramenta quantitativa de decisão importante (Figura 14) }\end{array}$ \\
$\begin{array}{l}\text { Ampliar o uso do QFD para } \\
\text { junto ao cliente }\end{array}$ & $\begin{array}{l}\text { Uso do QFD no processo de produção do cliente, relacionando as qualidades exigidas no QFD com } \\
\text { itens de controle dos equipamentos de embalamento do produto do cliente, resultando em uma } \\
\text { extensão da aplicação do método para além das fronteiras da empresa (ilustrado na Figura 15) }\end{array}$ \\
\hline
\end{tabular}

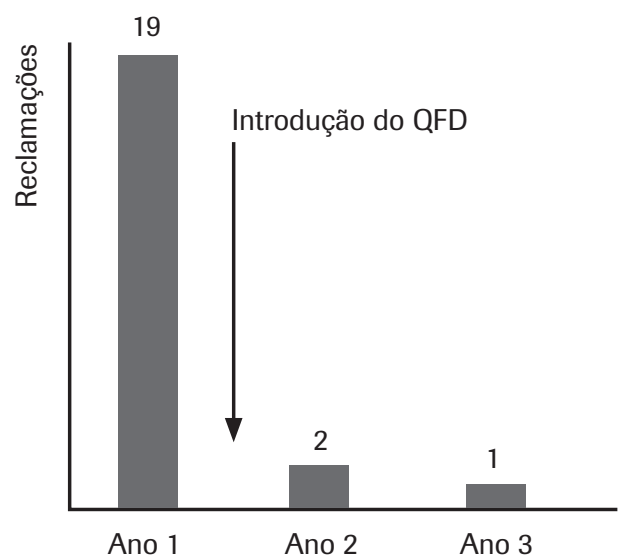

Figura 13: Redução nas reclamações. 


\section{CONCLUSÕES}

A partir da adoção da pesquisa-ação como abordagem metodológica, bem como pela constatação empírica de que o PDP da empresa foi reestruturado e o QFD aplicado em seus projetos de desenvolvimento, estas iniciativas auxiliaram a empresa na busca e tratamento das informações necessárias para desenvolver novos produtos, cumprindo então o objetivo proposto pelo trabalho.
No entanto, analisando criticamente, existiram algumas limitações impostas ao trabalho. Uma das maiores ameaças ao rigor na pesquisa ação é a falta de imparcialidade do pesquisador na intervenção realizada. Esta foi uma preocupação constante na condução do trabalho e difícil de ser contornada, por meio da busca constante de auto-disciplina, para não permitir que a profundidade de intervenção (dada pela extensão e grau de intensidade da interação com a empresa), o relacionamento positivo (alcançado com os membros da

\begin{tabular}{|c|c|c|c|c|c|c|}
\hline & Form. 1 (REF.) & Form. 2 & Form. 3 & Form. 5 & Peso C.Q. & OBS \\
\hline Brilho & & $(+)$ & $(+)$ & $(-)$ & 2,9 & O mínimo aceitável é de 83 \\
\hline Haze & & $(-)$ & $(-)$ & 1 & 2,1 & diferença de $0,09=1$ \\
\hline COF estático NT x NT & & $(+)$ & $(+)$ & $(+)$ & 3,2 & \\
\hline COF estático T x T 3,6 & & & & & 3,6 & \multirow[t]{2}{*}{ Definir com equipe } \\
\hline COF dinâmico NT x NT 3,2 & & & & & 3,2 & \\
\hline COF dinâmico T x T & & $(+)$ & $(+)$ & $(+)$ & 3,2 & \\
\hline Resist. à tração MD na ruptura & & $(-)$ & $(-)$ & $(-)$ & 7 & \\
\hline Alongamento MD na ruptura & & $(-)$ & $(-)$ & $(-)$ & 12,9 & \\
\hline Resist. à tração TD na ruptura & & $(+)$ & $(-)$ & $(+)$ & 6,6 & \\
\hline Alongamento TD na ruptura & & $(-)$ & $(-)$ & $(+)$ & 11,7 & \\
\hline Hot tack & & & & & & Teste não realizado \\
\hline Módulo 5\% MD & & I & I & I & 5,3 & diferença de 2,09=I \\
\hline Módulo 5\% TD & & $(+)$ & $(+)$ & $(+)$ & 5,3 & Form. 2 melhorou muito \\
\hline Resist. à prop. do rasgo MD & & $(-)$ & $(-)$ & 1 & 7,9 & diferença de $2=1$ \\
\hline Resist. à prop. do rasgo TD & & $(-)$ & $(-)$ & $(-)$ & 7,9 & \\
\hline Encolhimento MD & & $(-)$ & $(-)$ & $(-)$ & 0 & Form. 3 piorou muito \\
\hline Encolhimento TD & & $(-)$ & $(-)$ & I & 0 & diferença de 0,4 de $\mathrm{F} 1$ para F5 \\
\hline Resistência à Perfuração & & & & & 8 & \\
\hline Tensão Superficial & & & & & 0 & \\
\hline Ausência de Estática & & & & & 0,6 & \\
\hline Resistência de Selagem à $125^{\circ} \mathrm{C}$ & & $(-)$ & $(-)$ & 1 & 3,3 & \\
\hline Res. de Selagem face NT $\left(110^{\circ} \mathrm{C}\right)$ & & $(+)$ & $(+)$ & $(+)$ & 3,3 & \\
\hline Variação de espessura & & & & & 1,8 & \\
\hline CVA & $R \$ 4,49$ & $R \$ 5,38$ & $\mathrm{R} \$ 5,65$ & $R \$ 4,39$ & & F5 não testada em máquina \\
\hline Soma $(+)$ & & 6 & 5 & 6 & & \\
\hline Soma $(-)$ & & 9 & 10 & 5 & & \\
\hline Peso (+) & & 24,5 & 17,9 & 33,3 & & \\
\hline Peso (-) & & 52,8 & 59,4 & 30,7 & & \\
\hline
\end{tabular}

Figura 14: Matriz de decisão para seleção de conceito. 
organização) e maior influência do pesquisador nas decisões influenciasse de forma significativa nos resultados. De qualquer modo, considera-se que os objetivos do trabalho foram alcançados contribuindo com a literatura vigente, principalmente de cunho empírica relacionada à aplicação do QFD. Outro aspecto importante da pesquisa-ação, com relação ao objeto de análise, é o próprio contexto na forma dos aspectos culturais e éticos. Nesse sentido, o objeto de análise (empresa) e sua respectiva unidade de análise (processo de desenvolvimento de novos produtos) voluntária ou involuntariamente acabaram influenciando a pesquisa, uma vez que não é trivial desenhar claramente a fronteira entre o contexto e o tema pesquisado. No caso da presente pesquisa, essa limitação foi contornada pelas constantes reuniões de avaliação e a busca permanente da imparcialidade do pesquisador, apontada anteriormente. Considera-se também que, embora presente, essa limitação não trouxe implicações significativas para os resultados do trabalho de pesquisa.

Com base nos objetivos do trabalho, no delineamento metodológico da pesquisa e nas contribuições apontadas, pode-se citar os seguintes pontos conclusivos:

- A pesquisa-ação demonstrou ser uma abordagem adequada na condução deste trabalho, apesar das ameaças a sua validade, inerentes a esse tipo de pesquisa. A partir da busca constante do rigor metodológico, pode-se con- cluir que essa abordagem possibilitou o atendimento aos objetivos da pesquisa bem como o alcance de resultados positivos no campos teórico e prático.

- A restruturação do processo de desenvolvimento trouxe uma evolução em relação à versão anterior e proporcionou uma melhoria em geral para a empresa. Nesse sentido, pode-se concluir que o planejamento realizado por meio dos ciclos da pesquisa-ação resultou em uma estrutura organizacional mais robusta, onde o stage-gate demonstrou ser um modelo viável para essa estruturação, com as adaptações necessárias.

- O uso do QFD proporcionou um suporte adequado para as atividades de desenvolvimento de produtos, no sentido de organização e registro das informações, além de oferecer uma seqüência lógica para as atividades associadas às dimensões de mercado e de desenvolvimento, bem como a relação entre essas duas dimensões. Assim, pode-se concluir que o método possibilitou a obtenção dos benefícios apontados na literatura, bem como trouxe uma organização mais eficiente para as atividades de desenvolvimento.

Obviamente, o presente trabalho não pretendeu ser definitivo e, assim, sugerem-se as seguintes recomendações para desenvolvimentos futuros:

- Analisar a eficácia na implementação de processos de

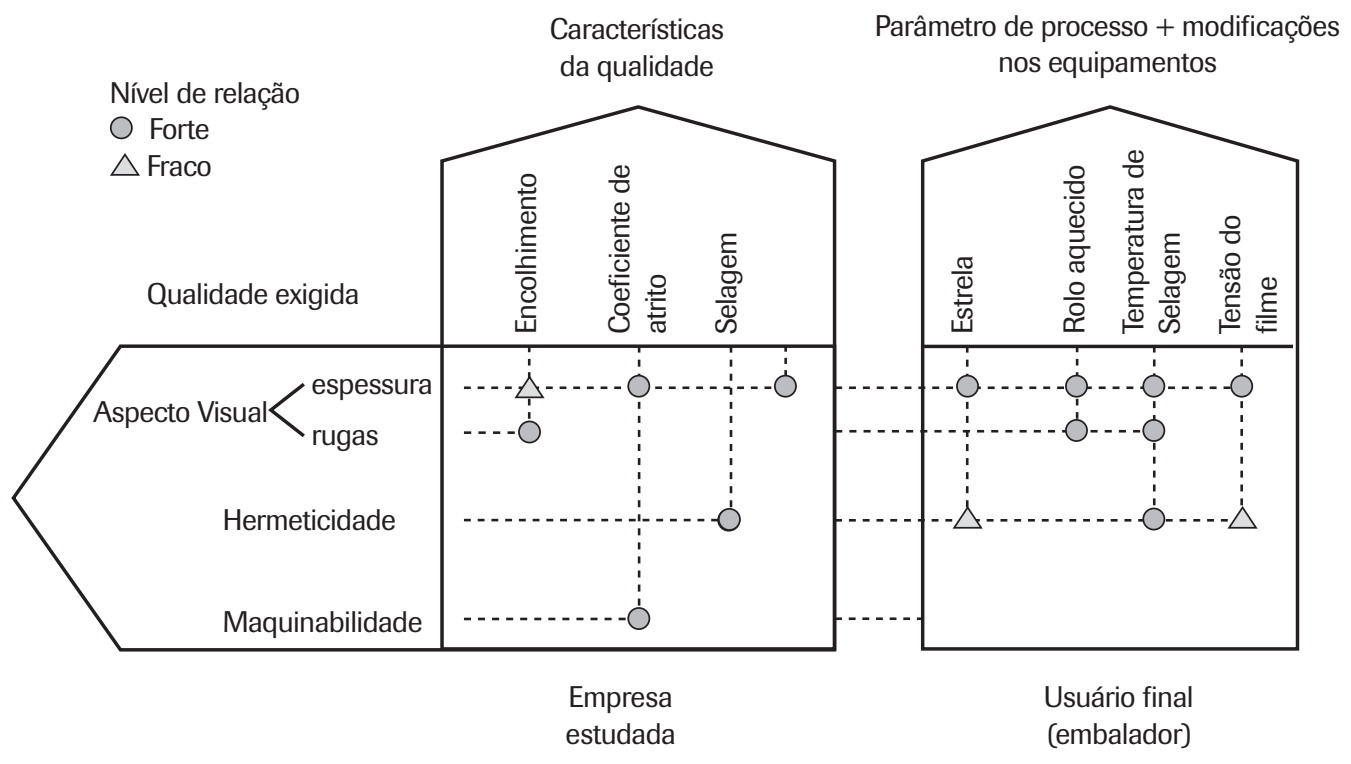

Figura 15: QFD na cadeia de fornecimento. 
desenvolvimento baseados no stage-gate. A questão da pesquisa estaria relacionada ao desenvolvimento de indicadores de desempenho visando mensurar os fatores de sucesso em tal implementação. Nesse caso poder-se-ia adotar como abordagem metodológica um levantamento tipo survey;
- Estender a aplicação do QFD nos desdobramentos de custos e confiabilidade pouco explorados na literatura. A questão da pesquisa estaria associada a uma proposta de implementação, podendo, inclusive, ser baseada na pesquisa-ação como nesse trabalho.

\section{Artigo recebido em 05/06/2007 Aprovado para publicação em 15/08/2008}

\section{AGRADECIMENTOS}

A consecução deste trabalho não seria possível sem o auxílio de diversas pessoas, para as quais gostaria de agradecer: aos professores Lin Cheng e Yoji Akao pelas discussões sobre QFD, aos profissionais da empresa e aos alunos de iniciação científica e mestrado que, direta ou indiretamente, trabalharam neste projeto de pesquisa. $\mathrm{O}$ autor também agradece ao CNPq e a Fundação Carlos Alberto Vanzolini pelo apoio concedido e também aos avaliadores do artigo que contribuíram significativamente para sua melhoria, especialmente a um dos avaliadores pelos questionamentos quanto à implementação do QFD e suas fases.

\section{REFERÊNCIAS}

AKAO, Y. (Ed.) Quality Function Deployment QFD - Integrating Customer Requirements into Product Design. Portland: Productive Press, 1990.

ANDRADE, M. M. Como Preparar Trabalhos para Cursos de Pós-graduação: Noções Práticas. São Paulo: Atlas, 2002.

APQP - Planejamento Avançado da Qualidade do Produto e Plano de Controle. $1^{\text {a }}$ edição brasileira. São Paulo: Instituto da Qualidade Automotiva, 1997.

BACELAR, S. R. B. et al. QFD: Estudo de caso em uma Empresa Prestadora de Serviços de apoio à Construção Civil. $C D-R O M$ do XXI Enegep, Salvador, 2001.

BENNETT, D.; LEE, S. J. Total Productive Maintenance Implementation in the Newspaper Industry: an Action Research Approach. In: VAN DIERDONCK, R.; VEREECKE, A. (Eds.), Operations Management: Crossing Borders and Boundaries - The Challenging Role of Operations, Universiteit Gent, Gent, p. 32-39, 2000.

BERGQUIST, K.; ABEYSEKERA, J. Quality Function Deployment (QFD) - A means for Developing usable Products. International
Journal of Industrial Ergonomics, v. 18, n. 4, p. 269-275, 1996.

BIER, I. D.; CORNESKY, R. Using QFD to Construct a Higher Education Curriculum, Quality Progress, v. 34, n. 4, p. 64-68, 2001.

BOUCHEREAU, V.; ROWLANDS, H. Methods and Techniques to help Quality Function Deployment (QFD). Benchmarking: An International Journal, v. 7, n. 1, p. 8-16, 2000a.

BOUCHEREAU, V.; ROWLANDS, H. Quality Function Deployment: the Unused Tool. Engineering Management Journal, v. 10, n. 1, p. 45-52, 2000 b.

BRATZ, M. et al. Aplicação do QFD em serviços de Consultas Eletivas da Santa Casa de Porto Alegre. CD-ROM do XXI ENEGEP, Salvador 2001.

CHAN, L. K.; WU, L. M. Quality Function Deployment: A Literature Review. European Journal of Operational Research, v. 143, n. 1, p. 463-497, 2002.

CHAN, L. K.; WU, L. M. A Systematic Approach to Quality Function Deployment with a Full
Illustrative Example. Omega - The International Journal of Management Science, v. 33, n. 2, p. 119-139, 2005.

CHECKLAND, P.; HOLWELL, S. Action Research: its Nature and Validity. Systems Practice and Action Research, v. 11, n. 1, p. 9-21, 1998.

CHENG. L. C. Caracterização da Gestão de Desenvolvimento do Produto: Delineando o seu Contorno e Dimensões Básicas. Anais do I/ Congresso Brasileiro de Gestão de Desenvolvimento de Produto, São Carlos, p. $1-9,2000$.

CHENG, L. C. QFD in Product Development: Methodological Characteristics and a Guide for Intervention. International Journal of Quality \& Reliability Management. v. 20, n. 1, p. 107122, 2003.

CHENG, L. C.; SARANTOPOULOS, I. A. QFD in Brazil: A Successful Diffusion Process into Organizations. Proceedings of the 1st International Symposium on QFD, Tóquio, $\mathrm{p}$. 77-84, 1995.

CHENG, L.C et al. QFD - Planejamento da Qualidade. Editora Líttera Maciel Ltda. Belo Horizonte, 1995. 
CLARK, K.B.; FUJIMOTO, T. Product Development Performace:Strategy, Organization and Management in the World Auto industry. Boston: Harvard Business School Press, 1991.

CLARK, K. B.; WHEELWRIGHT, S. C. Managing New Product and Process Development. New York: The Free Press, 1993.

COOPER, R. Winning at New Products Accelerating the Process from Idea to Launch. Perseus Books: Cambridge, 1993.

COOPER, R.; EDGETT, S. J.; KLEINSCHMIDT, E. J. Portfolio Management in New Product Development: Lessons from the Leaders - I. Research-Technology Management, v. 40, n. 5, p. 16-28, 1997a.

COOPER, R.; EDGETT, S. J.; KLEINSCHMIDT, E. J. Portfolio Management in New Product Development: Lessons from the Leaders - II. Research-Technology Management, v. 40, n. 6 , p. 43-52, 1997b.

COOPER, R. et al. Portfolio Management for New Products. Addilson-Wesley Publishing: Reading, 1998.

COOPER, R.; EDGETT, S. J.; KLEINSCHMIDT, E. J. New Problems, New Solutions: Making Portfolio Management more Effective. ResearchTechnology Management, v. 43, n. 2, p. 18-33, 2000.

COUGHLAN, P.; COGHLAN, D. Action Research for Operation Management. International Journal of Operations \& Production Management, v. 22, n. 2, p. 220-240, 2002.

CRISTIANO, J.; LIKER, J. K.; WHITE III, C. C. Customer-Driven Product Development through Quality Function Deployment in the US and Japan. Journal of Product Innovation Management, v. 17, p. 286-308, 2000.

DANILEVICZ, A. M.; RIBEIRO, J. L. D. Desdobramento da Qualidade: Um Estudo de Caso. CD-ROM do XVIII ENEGEP, Niterói, 1998.

DIAS, J. C. S.; MIGUEL, P. A. C. QFD: Perfil Histórico e Cronologia de Aplicações. Produto e Produção, v. 5, n. 2, p. 35-42, 2001.

DUARTE, L. C. S. et al. Desdobramento da Função Qualidade: Caso dos Laboratórios de Metrologia e Ensaios da Unijuí. $C D-R O M$ do XXI ENEGEP, Salvador, 2001.
EDEN, C.; HUXHAM, C. Action Research for Management Research. British Journal of Management, v. 7, p. 75-86, 1996.

FONSECA, A. V. M.; ANDERY, P. R. P. Considerações sobre Sistema de Medição orientado ao Desenvolvimento de Produtos e Gerenciamento de Projetos. CD ROM do $3^{\circ}$ Congresso Brasileiro de Gestão de Desenvolvimento de Produtos, Florianópolis, 2001.

FRANCESCHINI, F.; ROSSETTO, S. Tools and Support Techniques for Design Quality. Benchmarking: An International Journal, v. 6, n. 3, p. 212-219, 1999.

GERST, R. M. QFD in Large-scale Social System Redesign. International Journal of Quality \& Reliability Management, v. 21, n. 9, p. 959-972, 2004.

GINN, D.; ZAIRI, M. Best Practice QFD Application: an Internal/external Benchmarking Approach based on Ford Motors' Experience. International Journal of Quality \& Reliability Management. v. 22, n. 1, p. 38-58, 2005.

GOVERS, C. P. M. QFD not just a Tool but a Way of Quality Management. International Journal of Production Economics, v. 69, n. 2, p.151-159, 2001.

GRIFFIN, A. PDMA Research New Product Development Practices: Updating Trends and Benchmarking Best Practices. Journal of Product Innovation Management, v. 14, p. 429-458, 1997.

GUEDES, L. B. R. et al. Obtaining Countrywide Success through QFD Implementation in the Development Process of a Popular Brazilian Food Product. Proceedings of the 5th International Symposium on Quality Function Deployment, Belo Horizonte, p. 66-74, 1999.

GUNASEKARAN, A. An Integrated Product Development-Quality Management System for Manufacturing. The TQM Magazine, v. 10, n. 2, p. 115-123, 1998.

HAN, C. H. et al. Determination of Information System Development Priority using Quality Function Deployment. Computers \& Industrial Engineering, v. 35, n. 1-2, p. 241-244, 1998.

KARSAK, E. E. et al. Product planning in Quality Function Deployment using a Combined Analytic
Network Process and Goal Programming Approach. Computers \& Industrial Engineering, v. 44, n. 1, p. 171-190, 2002.

KARSAK, E. E. Fuzzy Multiple Objective Programming Framework to Prioritize Design Requirements in Quality Function Deployment. Computers \& Industrial Engineering, v. 47, n. 2-3, p. 149-163, 2004.

KARLSSON, C.; ÅHLDTRÖM. P. The Difficult Path to Lean Product Development. The Journal of Product Innovation Management, v. 13, n. 4, p. 283-295, 1996.

KATHAWALA, Y.; MOTWANI, J. Implementing Quality Function Deployment. Research and Concepts, v. 6, n. 6, p. 31-35, 1994.

KIM, K.; PARK, K.; SEO, S. A Matrix Approach for Telecommunications Technology Selection. Computers \& Industrial Engineering, v. 33, n. 3-4, p. 833-836, 1997.

LEE, S. F.; LO, K. K. e-Enterprise and Management Course Development using Strategy Formulation Framework for Vocational Education. Journal of Materials Processing Technology, v. 139, n. 1-3, p. 604-612, 2003.

LONDE, E. K. A.; COSENZA, C. A. N. Using POE and QFD Techniques to Improve Quality in Building Construction. Transactions from the 9 th Symposium on QFD, p. 321-329, Novi, 1997.

LOWE, A.; RIDGWAY, K. UK user's Guide to Quality Function Deployment. Engineering Management Journal, v. 10, n. 3, p. 147-155, 2000.

LU, M. H.; KUEI, C. H. Strategic Marketing Planning: a Quality Function Deployment Approach. International Journal of Quality \& Reliability Management, v. 12, n. 6, p.85-96, 1995.

LU, M. H. et al. Integrating QFD, AHP and Benchmarking in Strategic Marketing. Journal of Business and Industrial Marketing, v. 9, n. 1, p.41-50, 1994.

MARTINS, A.; ASPINWALL, E.M. Quality Function Deployment: an Empirical Study in the UK. Total Quality Management, v. 12, n. 5, p. 575-588, 2001.

MEYER, M. H. Revitalize your Product Lines through Continuous Platform Renewal. Research-Technology Management, v. 40, n. 2, p. 17-28, 1997. 
MIGUEL, P. A. C. Implementação da Gestão de Portfolio de Novos Produtos: Um Estudo de Caso. Produção, v. 18, n. 2, p. 388-404, 2008.

MIGUEL, P. A. C. et al. Desdobramento da Qualidade no Desenvolvimento de Filmes Flexíveis para Embalagens. Polímeros: Ciência e Tecnologia, v. 13, n. 2, p. 87-94, 2003.

MOYSÉS, G. L. R.; TURRIONI, J. B. Análise da Utilização do QFD no Setor de Serviços: Aplicação em um Sistema de Ensino. Anais do /l Congresso Brasileiro de Gestão de Desenvolvimento de Produtos, São Carlos, p. 326-333, 2000.

NASCIMENTO, P. T. S.; MARX, H. O Sistema de Inovação da Natura. Seminários em Administração, v. 5, São Paulo: USP, 2001. Disponível em: <http://www.ead.fea.usp.br/ Semead/Vsemead/Operações.htm >. Acesso em: 9 dez. 2004.

NOGUEIRA, T. M. et al. Quality Assurance: An Application of QFD to the Production Startup of a New Engine Line. Proceedings of the 5th International Symposium on QFD, Belo Horizonte, p. 26-83, 1999.

OLHAGER, J.; WEST, B. M. The House of Flexibility: using the QFD Approach to Deploy Manufacturing Flexibility. International Journal of Operations \& Production Management. v. 22, n. 1, p. 50-79, 2002.

ORMANESE, F. M. et al. Exploring a New Market Using QFD. Proceedings of the 8th Symposium on Quality Function Deployment, Novi, p. 1-10, 1996.

PAIVA, C.; CHENG L. O Emprego do QFD como Ferramenta para Implantação do Processo de Desenvolvimento de Novos Produtos em uma Pequena Empresa de Massas Alimentícias. CD-ROM do $3^{\circ}$ Congresso Brasileiro de Gestão de Desenvolvimento de Produto, Florianópolis, 2001.
PARKIN, N. et al. The Introduction of QFD in a UK Original Equipment Manufacturer. Managerial Auditing Journal, v. 17, n. 1, p. 4354, 2002.

PASSETO, S. C. et al. Desdobramento da Qualidade em Serviços: Melhorando o Desempenho de uma Academia de Ginástica. Anais do I Congresso Brasileiro de Gestão de Desenvolvimento de Produtos, Belo Horizonte, p. 167-176, 1999.

PETERS, A. J. et al. New Product Design and Development: A Generic Model. The TQM Magazine, v. 11, n. 3, p. 172-179, 1999.

PHILLIPS, R. et al. A Comparative Study of Six Stage-gate Approaches to Product Development. Integrated Manufacturing Systems, v. 10, n. 5, p. 289-297, 1999.

PMI - Project Management Institute. Guide of Project Management Body of Knowledge - PMBoK, 2000 (PMI Minas Gerais), v. 1.0 Disponível: http://www.pmimg.org.br. Acesso: 02 de fev. 2004.

POLIGNANO, L.; CASTANHEIRA, J. L. M. Desenvolvimento da Família de Produtos Suco Pronto: da Definição do Portfólio ao Produto. $C D$ ROM do $4^{\circ}$ Congresso Brasileiro de Gestão de Desenvolvimento de Produtos, Gramado, 2003.

PUGH, S. Total Design: Integrated Methods for Successful Product Engineering. Workingham: Addison-Wesley, 1991.

ROSATI, A. C. DFM e QFD Aplicados aos Sistemas de Distribuição de Energia e Sinal Automotivos (Chicotes Elétricos). Anais do IX Simpósio de Engenharia Automotiva - SIMEA, p. 395-404, São Paulo, 1997.

ROSS, P. J. The Role of Taguchi Methods and Design of Experiments in QFD. Quality Progress, v. 21, n. 6, p. 41-47, 1988.
ROZENFELD, H.; FORCELLINI, F. A.; AMARAL, D. C.; TOLEDO, J. C.; SILVA, S. L. ALLIPRANDINI, D. H.; SCALICE, R. K. Gestão de desenvolvimento de produtos: uma referência para a melhoria do processo. São Paulo: Saraiva, 2006.

SANTIAGO, L.; CHENG, L. C. Improving the Product Development System of Auto Suppliers Using the QFD Method. Proceedings of the 5th Int. Symposium on QFD, Belo Horizonte, $\mathrm{p}$. 182-191, 1999.

SANTOS, C.; PASCHOARELLI, L. C. Análise do Programa de Desenvolvimento de Produtos Sandvik a partir da aplicação do "Funil" de Desenvolvimento. Anais do // Simpósio de Engenharia de Produção - SIMPEP, Bauru, 1998.

SARANTOPOULOS, I. A. et al. Food Product Upgrade Using QFD. Transactions from the Eighth Symposium on Quality Function Deployment, Novi, 1996.

SASSI, A. C. Análise sobre a Inserção do QFD no Processo de Desenvolvimento de Produtos - Um Estudo de Caso em uma Empresa de Embalagens (Dissertação de Mestrado). Programa de Pósgraduação em Engenharia de Produção, UNIMEP, Santa Bárbara d'Oeste, 2005.

SONDA, F. A. et al. A Aplicação do QFD no Desenvolvimento de Software: Um Estudo de Caso. Produção, v. 1, n. 1, 2000.

TAN, K.; WISNER, J. A Study of Operations Management Constructs and their Relationships. International Journal of Operations \& Production Management, v. 23, n. 11, p. 1300-1325.

THIOLLENT, M. Metodologia da Pesquisa-ação. São Paulo: Cortez, 1997.

YEUNG, V. W. S.; LAU, K. H. (1997). Injection Moulding, C-MOLD'CAE Package, Process Parameter Design and Quality Function Deployment: A Case Study of Intelligent Materials Processing. Journal of Materials Processing Technology, v. 63, p. 481-487, 1997.

\section{SOBRE 0 AUTOR}

\section{Paulo A. Cauchick Miguel}

Departamento de Engenharia de Produção

Escola Politécnica - USP

End.: Av. Prof. Almeida Prado, Trav. 2, no 128 - Cidade Universitária - 05508-900 - São Paulo - SP

E-mail: cauchick@usp.br 